\title{
NON-LETHAL WEAPONS: SETTING OUR PHASERS ON STUN? Potential Strategic Blessings and Curses of Non-Lethal Weapons on the Battlefield
}

by

Erik L. Nutley, Lieutenant Colonel, USAF

August 2003

Occasional Paper No. 34

Center for Strategy and Technology

Air War College

Air University

Maxwell Air Force Base, Alabama 


\section{Report Documentation Page}

Form Approved

OMB No. 0704-0188

Public reporting burden for the collection of information is estimated to average 1 hour per response, including the time for reviewing instructions, searching existing data sources, gathering and maintaining the data needed, and completing and reviewing the collection of information. Send comments regarding this burden estimate or any other aspect of this collection of information,

including suggestions for reducing this burden, to Washington Headquarters Services, Directorate for Information Operations and Reports, 1215 Jefferson Davis Highway, Suite 1204, Arlington

VA 22202-4302. Respondents should be aware that notwithstanding any other provision of law, no person shall be subject to a penalty for failing to comply with a collection of information if it

does not display a currently valid OMB control number.

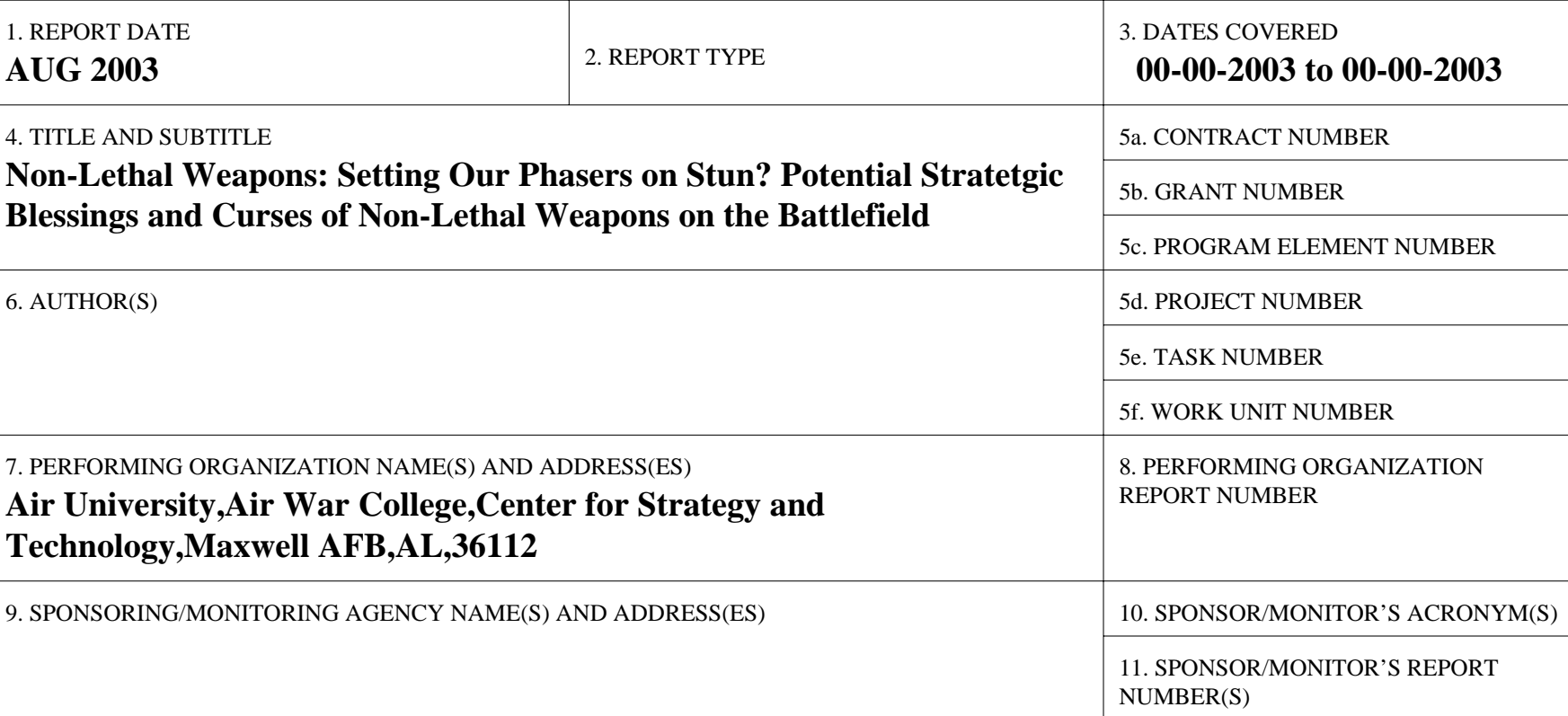

12. DISTRIBUTION/AVAILABILITY STATEMENT

Approved for public release; distribution unlimited

13. SUPPLEMENTARY NOTES

14. ABSTRACT

15. SUBJECT TERMS

16. SECURITY CLASSIFICATION OF:

a. REPORT

unclassified b. ABSTRACT unclassified c. THIS PAGE unclassified
17. LIMITATION OF ABSTRACT
18. NUMBER

OF PAGES

74 19a. NAME OF

RESPONSIBLE PERSON 


\title{
Non-Lethal Weapons: Setting Our Phasers on Stun? Potential Strategic Blessings and Curses of Non-Lethal Weapons on the Battlefield
}

\author{
Erik L. Nutley, Lieutenant Colonel, USAF
}

August 2003

The Occasional papers series was established by the Center for Strategy and Technology as a forum for research on topics that reflect long-term strategic thinking about technology and its implications for U.S. national security. Copies of No. 34 in this series are available from the Center for Strategy and Technology, Air War College, 325 Chennault Circle, Maxwell AFB, Alabama 36112, or on the CSAT web site at http://www.au.af.mil/au/awc/awcgate/awccsat.htm The fax number is (334) 953-6158; phone (334) 953-6460.

Occasional Paper No. 34

Center for Strategy and Technology

Air University

Maxwell Air Force Base, Alabama 36112 


\section{Contents}

\section{Page}



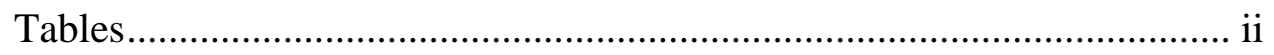



Acknowledgements........................................................................iv

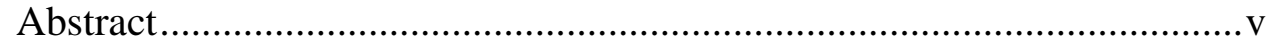

I. Introduction ..................................................................................... 1

II. Recent Developments in Non-lethal Weapons ................................... 7

III. State of the Science....................................................................... 13

IV. Strategic Advantages and Drawbacks of Non-Lethal Weapons.........25



VI. Non-Lethal Weapons in the War on Terrorism ................................47

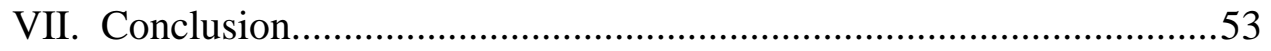





\section{Disclaimer}

The views expressed in this academic research paper are those of the author and do not reflect the official policy or position of Air University, the US government or the Department of Defense. In accordance with Air Force Instruction 51-303, it is not copyrighted, but is the property of the United States government. 


\section{Tables}

Page

Table 1: Classification of Non-Lethal Weapons ...................................13

Table 2: Existing and Emerging Non-Lethal Technologies ....................14

Table 3: High Emphasis Non-Lethal Technologies.................................16

Table 4: Summary of Treaties, Laws, and Regulations Concerning

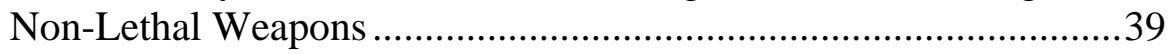

Table 5: Advantages of Non-Lethal Weapons Against Terrorists............50

Table 6: Drawbacks of Non-Lethal Weapons Against Terrorists ............51 


\section{Author}

Lieutenant Colonel Erik L. Nutley is currently the Military Advisor, Office of the Under Secretary of Defense (Acquisition, Technology, and Logistics) at the Pentagon. Colonel Nutley began his military career as a Distinguished Graduate of Officer Training School in 1982. He then attended the University of Washington, where he earned an M.S. degree in aeronautical engineering. After serving as applied aerodynamics engineer in the Air Force Flight Dynamics Laboratory at Wright-Patterson AFB, Ohio, he attended pilot training at Williams AFB, Arizona. Colonel Nutley went on to serve as an EC-135 Post Attack Command and Control System aircraft commander at Ellsworth AFB, South Dakota. Next, he was Assistant Professor of Aeronautics at the U.S. Air Force Academy, Colorado, where he was also instructor pilot in the T41 flight-screening program. After graduating as a Distinguished Graduate from Air Command and Staff College at Maxwell AFB, Alabama, in 1996, he transitioned to the C-141B at McChord AFB, Washington. There he served as 62d Airlift Wing Current Operations Director, Commander of the 62d Operations Support Squadron, and Deputy Commander of the 62d Operations Group. Colonel Nutley is a 2002 graduate of the Air War College at Maxwell AFB. 


\section{Acknowledgements}

I would like to express my appreciation to my Air War College faculty advisors Dr. Grant Hammond, Colonel (ret.) Theodore Hailes, and Lt Col John Geis for their invaluable encouragement and assistance. I also thank the personnel of the Joint Non-Lethal Weapons Directorate, particularly Major Noel Montgomery, Ms. Susan LeVine, and Mr. Humberto Rodriguez for their invaluable technical assistance. Finally, I am deeply indebted to my patient and loving family-my wife, Mawi, and children, Monica, Ryan, and Marian. 


\section{Abstract}

Though still in its infancy, the emergence of non-lethal technology in recent years has the potential to change the way wars are fought. Whether non-lethal weapons become a key component of a revolutionary transformation of the military depends on an analysis of their likely strategic effects. This paper is intended to provide an overview of some of the key issues facing the development and employment of non-lethal weapons for senior military and policy leaders. The paper begins with a discussion of recent technology developments for non-lethal weapons. Next, it describes current capabilities as well as the research, development, and procurement efforts needed to bring more non-lethal weaponry into the force structure. The discussion concludes that the current emphasis in non-lethal weapons is on defensive, tactical uses. The strategic advantages and drawbacks of non-lethal weapons - their potential to affect policy outcomes-are examined next. After that, topics including legal concerns and operational issues that need to be resolved before non-lethal weapons can be fielded on a greater scale are explored. The ability of non-lethal weapons to positively influence the global war on terrorism is also assessed. It is suggested that advantages of non-lethal weapons in these operations outweigh their drawbacks. Finally, a concluding assessment of the future of non-lethal weapons is offered. 



\section{Introduction}

The 11 September 2001 terrorist attack on the World Trade Center and Pentagon not only shattered lives and damaged America's sense of security, it also fundamentally altered notions about the best force structure to protect U.S. interests. The new administration was already engaged in a process to redefine the nation's defense structure to make it more responsive to challenges of the post-Cold War global security environment. The attack refocused attention on what is likely to be a major threat to U.S. interests for the foreseeable future. Hence, the 30 September 2001 report of the Quadrennial Defense Review, Secretary of Defense Donald Rumsfeld's most definitive statement to date about transforming America's defense establishment for the $21^{\text {st }}$ century, made special mention of the attacks as confirming the new emphasis on "homeland defense, on surprise, on preparing for asymmetric threats, on the need to develop new concepts of deterrence, on the need for a capabilities-based strategy, and on the need to balance deliberately the different dimensions of risk." ${ }^{1}$ Further, the report stressed the need for transformation of the U.S. Armed Forces through "exploitation of new approaches to operational concepts and capabilities," which can fundamentally change the ways war is waged. ${ }^{2}$ Finally, the report noted that the transformation has "intellectual, social and technological dimensions" and that "fundamental changes in the conceptualization of war as well as in organizational culture and behavior are usually required to bring it [transformation] about."3

Given this call to consider new approaches to warfare, a fresh look at a variety of weapons designated "non-lethal" is in order. Are these weapons needed in order to keep U.S. armed forces viable in the $21^{\text {st }}$ Century? As will be shown, non-lethal weapons are not entirely new. However, the vast majority of weapons used throughout the history of warfare have been of the lethal variety-those designed to kill people and destroy materiel. Non-lethal weapons, though arguably still in their infancy, are now gaining momentum and receiving the attention of military leaders and national security thinkers. There is a growing consensus that this type of weapon is needed, at least in military operations such as peacekeeping roles. Whether they play a prominent role in tomorrow's military force structure in a more wide-ranging set of 
circumstances spanning the spectrum of conflict depends on several factors, such as legal and operational issues. More fundamental, however, is whether the benefits of using non-lethal weapons are deemed to outweigh the drawbacks at the strategic level. These strategic issues, the potential pros and cons of fielding and using this type of weaponry, are the central focus of this paper. Before any analysis can be made as to the usefulness of these weapons, it is important to make clear precisely what is meant by "non-lethal weapons."

\section{Defining Non-Lethal Weapons}

Defining "non-lethal weapons" is no easy task, and there is widespread disagreement about the exact meaning and usage of the term. Department of Defense (DOD) policy defines non-lethal weapon systems as those "that are explicitly designed and primarily employed so as to incapacitate personnel or materiel, while minimizing fatalities, permanent injury to personnel, and undesired damage to property and the environment." 4 Though the DOD definition will be used throughout this paper, there are several aspects of the term's usage that bear clarification. First, unlike their lethal counterparts that are designed to destroy targets primarily through blast, penetration, and fragmentation, non-lethal weapons prevent their targets from functioning through means other than gross physical destruction. 5 Second, though the term "non-lethal" seems to imply that no fatalities will ever be caused by these weapons, this is not the case. Rather, non-lethal weapons are intended to significantly reduce the probability of these consequences compared to traditional weapons. In fact, DOD policy explicitly states that non-lethal weapons "shall not be required to have a zero probability of producing fatalities or permanent injuries."6 The policy goes on to point out, however, that "while complete avoidance of these effects is not guaranteed or expected, when properly employed, non-lethal weapons should significantly reduce them as compared with physically destroying the same target."7 In short, just as their lethal counterparts sometimes fail to kill, non-lethal weapons can sometimes be deadly. The description, therefore, applies to the intent rather than the effect. ${ }^{8}$ Third, damage to property and the environment is not completely precluded by these weapons. In fact, many are designed to cause property damage. For example, a directed energy weapon targeting a missile system could disable its electrical components while remaining below the temperature threshold required to cause an explosion. Fourth, 
unlike lethal weapons, whose intent is to cause death, permanent injury, or irreversible destruction of a system, reversibility is an important aspect of non-lethal technologies. ${ }^{9}$ While this is especially the case in counterpersonnel weapons, it also normally applies to those that target materiel. For example, in the case of the missile system mentioned above, much of the system could, in theory, be salvaged after a non-lethal attack. Fifth, as the term "weapon" implies, things rather than activities are being considered. Consequently, the definition does not include many nonlethal activities or operations that support the application of force on the battlefield. Therefore, information warfare, psychological operations, electronic warfare (except for non-lethal electronic attack), ${ }^{10}$ and communications operations are all activities that are not included in the definition, even though some of the literature does include these activities under the rubric of non-lethal weapons. A final definitional issue to highlight is that the term weapon itself is open to interpretation. Oddly enough, no official definition of weapon is given in the Department of Defense Dictionary of Military and Associated Terms. Therefore, one could argue that certain non-lethal systems such as rigid foams, obscurants, holograms, markers and the like are not actually weapons. The issue is not trivial, as it has the potential to influence policies concerning the use of non-lethal systems and even their legality relative to international law, which will be discussed later. For the sake of consistency, this paper will regard all non-lethal systems, whether they are technically weapons or not, as non-lethal weapons.

To summarize, the principle characteristics of non-lethal weapons that distinguish them from their lethal counterparts and other non-lethal activities are as follows:

- Delay, disrupt, disorient, deny versus destroy

- Reversible effects

- Weapons (things), not activities

- Intent, rather than effect is important

- Significantly reduce (rather than eliminate) death, destruction, and permanent injury

\section{Alternative Terms}

To avoid the perception that fatalities can be eliminated, many have proposed terms other than non-lethal. Alternative terms that have 
been put forward include less-lethal, less-than-lethal, and sub-lethal effects weapons, all terms that more accurately describe the intent of these weapons. In 1989, non-lethal weapon proponent John B. Alexander put forward the words anti-materiel technology to describe weapons designed to stop the machines of war rather than to kill enemy soldiers. ${ }^{11}$ However, this term is obviously a sub-set of non-lethal weapons, since it does not include any anti-personnel class of non-lethal weapons. Another term, Soft Kill, was used to denote attacks that limit destructive effects, also a somewhat different idea. ${ }^{12}$ A similar concept was Mission Kill, which denoted rendering a military system, person, or unit incapable of performing its mission at a time or place required. ${ }^{13}$ This term, however, suffers from being overly broad and vague-there is a plethora of ways to "kill" a mission, including conventional, lethal means. United States Joint Forces Command uses the term non-kinetic technology to describe a similar, but arguably broader, set of weapons. One author has dubbed these "weapons that hinder the enemy, but don't go boom, such as ones that destroy computer files, disrupt communications or wipe out bank accounts." $^{\text {I4 }}$ It should be noted, however, that this term includes many weapons not normally included in the definition of non-lethal, such as computer viruses and lethal-power lasers, and conversely, would not include non-lethal kinetic weapons. Though the prevailing term of nonlethal clearly has serious drawbacks, changing it at this point would prove very challenging, as it has made its way into much of the literature, official military publications, and everyday usage. For this reason, the Joint Non-Lethal Weapons Directorate, the organization that oversees DOD non-lethal weapon activities, concludes that the term non-lethal seems to be well entrenched and would be difficult to change at this point. $^{15}$

\section{Historical Examples}

In order to more fully explore the meaning of non-lethal, it is instructive to consider examples that have been put forward as historical precedents for the use of non-lethal weapons. Many such examples have been suggested; however, most of the weapons cited do not technically meet the definition of non-lethal adopted by the DOD and used in this report. ${ }^{16}$ For example, smoke has been proposed as an ancient precursor to today's non-lethal technologies, but whether it qualifies under the current definition depends on its usage. If used as a signal for 
communications, it would not conform to the current definition; smoke signals are clearly not intended to incapacitate the recipient. On the other hand, if a commander uses smoke to provide cover for attacking forces, it might qualify since its intent is to disable or restrict the vision of one's opponent. Such “obscurants” are, in fact, listed as non-lethal weapons. Smoke could also fit the current non-lethal definition if it were used to flush an enemy out of a building or cave. However, since smoke can also be highly toxic, the chief issue is that of intent. Some suggest that the defoliants used by the British Army in Malaya in the 1940s and 1950s and by the U.S. in Vietnam are examples of non-lethal weapons. ${ }^{17}$ In this case, however, the objective for using these herbicides was to destroy the food sources and cover of communist insurgents. Since this employment is not fundamentally different from other time-honored procedures to destroy crops (such as "scorched earth," for instance), their use is not consistent with the current definition either. Another proposed example of non-lethal weapons use occurred under Israel's military leader, Joshua, against Jericho circa 1400 B.C. However, since the sounding of trumpets caused the city's wall to "fall down flat (see Joshua 6:20)," this would appear to be an example of a rather unconventional lethal weapon rather than a non-lethal one per the DOD definition. ${ }^{18}$ Finally, the U.S. military used loud rock music to drive Manuel Noriega from the building he was holed up in in Panama. ${ }^{19}$ However, whether this is truly disabling is debatable. It would probably be more accurate to classify blaring music as a psychological weapon, which is usually not included as a category of non-lethal weapons.

There are a few historical cases, however, that do accurately fit within the modern definition of non-lethal weapons. One example is CS gas (0-chlorobenzalmalononitrile), a white solid powder usually mixed with a dispersal agent like methylene chloride, which carries the particles through the air. CS is a tear gas used as a riot control device by British forces in Cyprus in 1958 and also by the U.S. Army to complement lethal force to flush combatants out of caves and tunnels during the Vietnam War. Rubber bullets used against Northern Ireland rioters in the 1970s are another example. $^{20}$ Obviously, both of these weapons types are used routinely by law-enforcement officials, as are wooden batons. Another excellent example is the non-lethal variant of the Tomahawk missile used during the 1991 Gulf War that released spools of carbon fibers above electrical plants, causing short-circuits which, in turn, disrupted electrical power production. $^{21}$ Yet another operational use of non-lethal weapons 
was demonstrated on 4 April 2000, when soldiers of the 709th Military Police Battalion successfully employed non-lethal measures to disperse a hostile crowd during real-world operations in Kosovo. ${ }^{22}$

As can be seen from these examples, non-lethal weapons are not entirely new. With few exceptions, however, mankind's experience with these types of weapons spans only the last few decades. Consequently, the non-lethal weapons being envisioned today mark a significant break with the past. Although they have been thought about in military circles since the 1960s, as the next section will show, it was not until the 1990s that non-lethal weapons started to receive significant attention from senior leaders. ${ }^{23}$ 


\section{Recent Developments in Non-lethal Weapons}

According to U.S. Army War College Professor Steven Metz, the Secretary of Defense's formation of the Non-Lethal Warfare Study Group in 1991 marked a major milestone in the United States defense establishment's interest in non-lethality. ${ }^{24}$ Overseen by the Under Secretary of Defense for Policy and chaired by the Assistant Deputy Under Secretary of Defense for Policy Planning, the group supported policies and programs designed to foster the development and fielding of non-lethal weapons. However, the Pentagon was unwilling to make a major commitment at the time, and when the Under Secretary of Defense for Acquisition argued that existing programs could adequately handle non-lethal weapons, the study group's recommendations were shelved.

More recently, the mounting operational interest in non-lethal weapons was spurred by the perceived need for such weapons during the 1995 United Nations Operation UNITED SHIELD in Somalia. Marine Corps Lieutenant General Anthony Zinni was charged with protecting the final withdrawal of forces from Somalia after Operation RESTORE HOPE, which began as a humanitarian mission to disperse food and alleviate widespread starvation in December $1992 .^{25}$ General Zinni explored the prospects of using non-lethal weapons and asked for a quick response to field a capability. The Marine Corps and the Army teamed to provide General Zinni with "off-the-shelf" non-lethal technologies, enabling the first operational use of these new technologies in and around

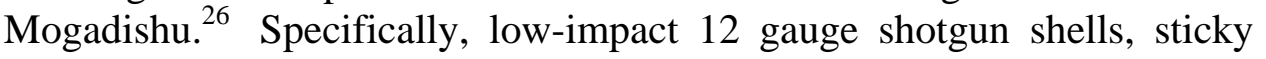
and aqueous foams from Sandia National Laboratory, and a low-energy laser system to intimidate suspected snipers were provided to warfighters. $^{27}$ "Although the effects of these non-lethal weapons were marginal, General Zinni's aggressive support added credibility to the effort to field non-lethal weapons."28 He stated that he would never go to on another peace support mission without them and that there was an urgent need for more such weapons. ${ }^{29}$ The eighteen Rangers that lost their lives fighting in the streets of Mogadishu on 3 October 1993 is often cited as the primary impetus for developing non-lethal weapons. What is less often considered, in the United States at least, is that some 300 Somali citizens, many of them civilians, died that same night. ${ }^{30}$ Even more to the point, by the end of 1994, more than 130 U.N. peacekeepers would die attempting 
to end the starvation in Somalia and scores of Somalis would share a similar fate. ${ }^{31}$

In a speech given at the Non-Lethal Defense Conference II on 7 March 1996, General Sheehan, Supreme Allied Commander Atlantic and Commander, U.S. Atlantic Command, also expressed the need for new capabilities in today's changing security environment. He stated that "this nation should no longer tolerate dedicated, professional troops equipped with the wrong tools for new, more complex missions....It is time to accept the challenge to meet the changing realities before us. Non-lethal weapons must be part of today's tool kit."32 The issuance of DOD Policy Directive 3000.3: Policy for Non-Lethal Weapons on 9 July 1996 furthered the evolution of thinking on the use of non-lethal weapons on the battlefield. The directive established DOD policy for non-lethal weapons, laying out joint service responsibilities and providing guidelines for the development and employment of non-lethal weapons. The directive designated the Commandant of the Marine Corps as Executive Agent (EA) for the DOD Non-Lethal Weapons Program, with the responsibility of providing "program recommendations and for stimulating and coordinating non-lethal weapons requirements."33

On 21 January 1997, the Joint Non-Lethal Weapons Directorate was established to manage the day-to-day activities of overseeing Joint Non-Lethal Weapons Program. The directorate, located at Quantico Marine Base, Virginia, was charged with conducting technology assessments, providing oversight of acquisition activities, and maintaining liaison with the services, combatant commanders, and other defense agencies and laboratories, as well as with foreign non-lethal weapon programs. $^{34}$

A major milestone in the conceptualization and development of potential non-lethal technologies was reached with the completion of the Joint Non-Lethal Weapons Program's Joint Mission Area Analysis/Joint Mission Need Analysis [hereafter, abbreviated JMAA] report. The final report for this rigorous joint effort, begun in 1999, was published in the spring of 2001. The Commandant of the Marine Corps had recognized the need for a detailed, thorough end-to-end analysis of the potential military contributions of non-lethal capabilities. Consequently, he directed that an analysis be conducted to express the needs of Combatant Commanders, Joint Force Commanders and the Service forces they employ in executing their assigned missions. ${ }^{35}$ The goals of the analysis included synchronizing non-lethal weapon efforts with Joint Vision Implementation 
Plan and Requirements Generation System, identifying non-lethal operational deficiencies and potential needs, assessing non-lethal weapon technologies, examining science and technology requirements, and identifying common needs for the development of Joint Non-Lethal Weapons requirements. ${ }^{36}$ Concurrently, the Joint Requirements Oversight Council (JROC) endorsed the need for a study to identify Joint and Service requirements for non-lethal capabilities. Panel participants included representatives from the Unified Commands, Services, Joint Staff, DOD agencies, and other departments within the government that have a stated interest in non-lethal capabilities. Based on analysis conducted over the course of six months, the panel developed a series of key findings and recommendations that constitute a major landmark in DOD thinking regarding non-lethal weapons and lay the course for developing future capabilities. The panel findings include the following: ${ }^{37}$

- Non-lethal capabilities apply and have expressed utility across all types of Military Operations Other Than War and Major Theater War.

- Non-lethal capabilities apply across the hierarchy of Joint and Service tasks - covering the strategic, operational, and tactical levels.

- Non-lethal capabilities have clear applications for tasks associated with Force Protection, Movement/Maneuver and Employing Forces/Fires, with fewer applications for Intelligence, Surveillance, and Reconnaissance (ISR) and Command and Control (C2).

- Non-lethal capabilities complement lethal weapons and, for some tasks, offer advantages or unique contributions. This is true across the spectrum of threats and crises.

- Non-lethal capabilities provide a unique capability that allows forces to break the cycle of violence and revenge that provides the catalyst for prolonged or systematic conflict. This has significant implications for U.S. forces conducting operations across the spectrum of conflict.

- Non-lethal capabilities support the accomplishment of mission tasks and operational needs in combatant commander war plans at the tactical level and have potential non-lethal application at the operational and strategic levels. Treaties and conventions developed prior to the advent of military non-lethal capabilities may impact the development of selected technologies, e.g., calmatives.

- National policy and domestic laws may require review.

- High tech systems are necessary for needs satisfaction. 
- A dedicated, focused joint science and technology (S\&T) effort for non-lethal capabilities does not exist.

- Existing modeling and simulation tools are not adequate for the full assessment and evaluation of non-lethal capabilities in regards to human effects.

- Current acquisition regulations and guidelines may not embrace the peculiarities of non-lethal capabilities development (e.g., human effects assessments).

- Ranges of current non-lethal weapons programs and systems only extend to 100 meters.

The panel also found that there were several areas in which non-lethal capabilities may offer advantages or unique contributions relative to lethal weapons: $^{38}$

- Attaining a military objective while minimizing unnecessary loss of human life and gross physical damage;

- Countering the use of non-combatants used as human shields;

- Achieving desired effects with precision accuracy on targets in restrictive fire areas or in constrained environments such as Rules of Engagement (ROE) or treaty restrictions;

- Reducing collateral damage;

- Providing new capabilities to address features within the complex urban environment;

- Attaining counter-mobility and area denial, with advantages stemming from reversibility of effects;

- Degrading Weapons of Mass Destruction (WMD) production and delivery systems while reducing risks of NBC release; and

- Protecting forces and facilities.

Finally, the team evaluated non-lethal programs and resources and identified the following shortfalls: ${ }^{39}$

- No venue currently exists for joint funding of a dedicated, focused S\&T effort for non-lethal capabilities.

- Current tools are not adequate for the full assessment and evaluation of non-lethal capabilities in regards to human effects and specific operational contributions. 
- Current acquisition regulations and guidelines may not embrace the peculiarities of non-lethal capability development (i.e., human effect assessments).

Based on their study, the panel members made several recommendations for future non-lethal development efforts. In addition to advocating continued actions in the joint community to define the need for the weapons' capabilities, the panel made the following recommendations: ${ }^{40}$

- General support tools, such as models for human effects and operational analysis support, should be expeditiously advanced and developed.

- Near-term acquisition efforts should be focused on providing a standoff capability to delivery of non-lethal capabilities beyond small arms range. Adaptation of current delivery systems is proposed for analysis.

- A focused joint S\&T effort that concentrates on state-of-the-art nonlethal technologies, such as directed energy, is needed.

- The DOD and Services should review resource allocations for adequacy of addressing non-lethal weapon needs.

- The Joint Non-Lethal Weapons Program (JNLWP) should ensure the analysis of and subsequent development of non-lethal capabilities are done in coordination with other capability assessments such as urban operations, psychological operations, information warfare and threat reduction.

- The JNLWP should support the development of existing joint doctrine for the application of non-lethal capabilities at all levels of war.

- The JNLWP, in coordination with the Joint Staff, should incorporate instruction in the military applications of non-lethal capabilities into the Joint Program of Military Education (JPME).

- The Services, combatant commanders, and the Joint Staff should initiate Advance Technology Demonstrations (ATDs) and Advance Concept Technology Demonstrations (ACTDs) for mature non-lethal technologies.

- The office of the Secretary of Defense, coordination with the Joint Staff and other government agencies review and modify/change policies as appropriate to allow for the early use of non-lethal capabilities in a preclusionary role. 
The JMAA report signals an intensification of the level of effort invested in exploring non-lethal capabilities during the last few years. The next section will present where the technology currently stands. 


\section{State of the Science}

As shown in Table 1, non-lethal weapons can be broadly divided into two major capability categories. As the name implies, counterpersonnel weapons are those designed to work against people, either by incapacitating them, or by compelling them to move or stay away. Similarly, counter-materiel weapons are designed either to disable or to deny an area to vehicles (ground, sea, or air). Within each of these core capabilities are functional areas that describe key desired roles for these weapons.

Table 1: Classification of Non-Lethal Weapons ${ }^{41}$

\begin{tabular}{|l|l|}
\hline Core Capability & Functional Area with Core Capability \\
\hline Counter-Personnel & $\begin{array}{l}\text { Crowd control } \\
\text { Clear facilities of personnel } \\
\text { Incapacitate personnel } \\
\text { Deny an area to personnel }\end{array}$ \\
\hline Counter-Materiel & $\begin{array}{l}\text { Deny an area to vehicles, vessels, aircraft } \\
\text { Disable equipment and facilities }\end{array}$ \\
\hline
\end{tabular}

Another way to classify these weapons is according to the technologies upon which they are built. Table 2 shows non-lethal technologies that have either been developed or are envisioned for the future. The table is the result of the JMAA's Operations and Threat Working Group's efforts to identify all existing, emerging, and collateral non-lethal technologies. The basic categories of technologies are electromagnetic, chemical, acoustic, and mechanical or kinetic. Combined technologies make use of more than one of the technologies. Ancillary technologies refer to those that don't fit neatly into the other categories or are weapon enablers. Note again that one could debate whether some of these items technically fit into the official DOD definition of a non-lethal weapon (markers, for example). 
Table 2: Existing and Emerging Non-Lethal Technologies ${ }^{42}$

\begin{tabular}{|c|c|c|c|}
\hline Electromagnetic & Chemical & Acoustic & $\begin{array}{c}\text { Mechanical and } \\
\text { Kinetic } \\
\end{array}$ \\
\hline $\begin{array}{l}\text { ELECTRICALS } \\
\text { Pulsed current } \\
\text { Sticky Shocker } \\
\text { Stun guns } \\
\text { Taser mine } \\
\text { Direct current } \\
\text { RADIO FREQUENCY } \\
\text { Non-nuclear EMP } \\
\text { MICROWAVE } \\
\text { High Power } \\
\text { Microwaves } \\
\text { MILLIMETER WAVE } \\
\text { Millimeter wave } \\
\text { projector } \\
\text { INFRARED } \\
\text { Chem. oxygen iodine } \\
\text { lasers } \\
\text { CO2 lasers } \\
\text { HF/DF lasers } \\
\text { Solid state lasers } \\
\text { VISIBLE } \\
\text { Laser scattering } \\
\text { obscuration } \\
\text { Laser illuminators } \\
\text { Holograms } \\
\text { Laser light bullets } \\
\text { Isotropic radiators } \\
\text { Flashes and flares } \\
\text { Strobes } \\
\text { ULTRAVIOLET } \\
\text { Laser Ionizer }\end{array}$ & $\begin{array}{l}\text { OBSCURANTS } \\
\text { Smokes } \\
\text { REACTANTS } \\
\text { Supercorrosives } \\
\text { Combustion alteration- } \\
\text { air/fuel } \\
\text { Combustion alteration- } \\
\text { fuel viscosity } \\
\text { Lubricant contaminants } \\
\text { Depolymerizers } \\
\text { Embrittlers } \\
\text { Emulsifiers } \\
\text { MALODERANTS } \\
\text { Skatole } \\
\text { Mercaptan } \\
\text { CALMATIVES } \\
\text { RIOT CONTROL AGENTS } \\
\text { OC (pepper spray) } \\
\text { CS } \\
\text { CN, Mace } \\
\text { ANTI-TRACTION FOAMS } \\
\text { Sticky foams } \\
\text { Rigid foams } \\
\text { THERMOBARRIC } \\
\text { COMPOUNDS } \\
\text { NANOPARTICLES } \\
\text { Magnesium oxide }\end{array}$ & $\begin{array}{l}\text { AUDIBLE } \\
\text { INFRASONIC } \\
\text { ULTRASONIC }\end{array}$ & $\begin{array}{l}\text { BARRIERS } \\
\text { Caltrops } \\
\text { Tire spikes and strips } \\
\text { ENTANGLEMENTS } \\
\text { Portable vehicle } \\
\text { arresting barrier } \\
\text { Running gear } \\
\text { entanglement system } \\
\text { Net mines } \\
\text { CLOGGERS } \\
\text { Vessel Exhaust stack } \\
\text { blocker } \\
\text { BLUNT IMPACT } \\
\text { DEVICES } \\
\text { Rubber balls } \\
\text { Modular crowd control } \\
\text { munitions } \\
\text { 40mm crowd dispersal } \\
\text { munitions } \\
\text { 66 mm vehicle launched } \\
\text { NL grenade } \\
\text { Liquid filled } \\
\text { Bean bag } \\
\text { Baton } \\
\text { Water stream cannon }\end{array}$ \\
\hline \multicolumn{2}{|c|}{ Combined Technologies } & \multicolumn{2}{|c|}{ Ancillary Technologies } \\
\hline \multicolumn{2}{|c|}{$\begin{array}{l}\text { Flash Bang Devices } \\
\text { Multi-sensory Distraction Device } \\
66 \mathrm{~mm} \text { Vehicle Launched Grenade }\end{array}$} & \multicolumn{2}{|c|}{$\begin{array}{l}\text { MARKERS } \\
\text { Dyes - Liquid, foam, smoke } \\
\text { Fluorescent } \\
\text { Invisible - UV light visible } \\
\text { Paint ball guns } \\
\text { NON-LETHAL CASINGS } \\
\text { ENCAPSULANTS } \\
\text { TAGGERS - ACTIVE }\end{array}$} \\
\hline \multicolumn{4}{|c|}{ Italicized text signifies existing technologies } \\
\hline
\end{tabular}


Having determined the master list of all current and future nonlethal technologies, the working group assessed what kinds of technologies might offer capabilities most useful to future military forces. They looked at major platforms, delivery modes that could be employed, and specific non-lethal payloads. They found that the greatest potential for near term application of existing and emerging technologies include, but are not limited to:

- Electromagnetic Systems: High power microwaves, millimeter waves, infrared, visible (lasers and lights), and emitting taggant/trackers.

- Chemical-Based Substances: Malodorants, calmatives, riot control agents, anti-traction substances, foams, and nanoparticles

- Mechanical and Kinetic Devices: Barriers, entanglements, doggers and blunt impact devices

- Enabling Technologies: Microencapsulation, combustible/ frangible casings, and a variable velocity launch capability

Finally, having identifying all the current non-lethal technologies as well as emerging and collateral technologies, the group set out to select a master list of candidate technologies that should receive special attention. The list was derived from a number of factors. ${ }^{43}$ First, assessments were made as to where particular technologies offered the best opportunities for high payoffs. This involved determining the number of times the payload was chosen as an element of a candidate system for all assessed mission tasks and how many delivery modes were deemed feasible for each payload. In addition, selection criteria included technologies that would provide a unique capability not available through other means, those that would be highly effective from a technical standpoint, and technologies that would have a higher probability of being successfully developed. The resulting list shown in Table 3 contains brief statements on the potential operational contribution, rationale for selection, and areas most needing concentrated research. 
Table 3: High Emphasis Non-Lethal Technologies ${ }^{44}$

\begin{tabular}{|c|c|}
\hline Technology & Rationale \\
\hline $\begin{array}{l}\text { 1. Millimeter Wave } \\
\text { Electromagnetic } \\
\text { Radiation }\end{array}$ & $\begin{array}{l}\text { Previously classified. See Active Denial System under Advanced Concept } \\
\text { Technology Demonstrations below. }\end{array}$ \\
\hline $\begin{array}{l}\text { 2. Chemical } \\
\text { Oxygen Iodine } \\
\text { Lasers }\end{array}$ & $\begin{array}{l}\text { COIL technology offers unique contributions to the non-lethal counter-materiel and } \\
\text { counter-capability areas by providing the capability to strike targets with ultra- } \\
\text { precision, controllable effects from long standoff ranges while minimizing collateral } \\
\text { damage. A derivative of the technology being used on the Air Force Airborne Laser } \\
\text { program, COIL has the highest technical maturity and offers the greatest potential for } \\
\text { implementation in the near to midterm. It is the central element of the Advanced } \\
\text { Technology Laser ACTD. Technical challenges include scaling down of the laser } \\
\text { gain module, beam conditioning and control in a dynamic motion environment, and } \\
\text { management of the chemical process effluents. Technical risk is considered medium. }\end{array}$ \\
\hline 3. Anti-Traction & $\begin{array}{l}\text { Anti-traction or slippery substances can provide the capability to inhibit the fire } \\
\text { movement of vehicles or individuals through treated areas. This would provide a } \\
\text { capability to deny access to or through an area in a number of operationally useful } \\
\text { situations. Although some development has taken place and the concept has been } \\
\text { successfully demonstrated, additional work is necessary to improve the persistence } \\
\text { and concentration of these materials in operational environments. Anti-traction } \\
\text { material payloads can be readily integrated into a number of existing ground and air } \\
\text { delivery systems and platforms and can be made operational in the near term. }\end{array}$ \\
\hline $\begin{array}{l}\text { 4. Non-Lethal } \\
\text { Delivery } \\
\text { /Deployment }\end{array}$ & $\begin{array}{l}\text { Non-lethal munitions must be capable of deploying and dispersing their payloads in a } \\
\text { non-lethal and controlled manner. Technologies that reduce the kinetics of the } \\
\text { delivery process such as frangible and combustible materials enable the development } \\
\text { of munition casings that break up into many low mass, low-velocity fragments. Other } \\
\text { options include use of materials that are combusted during payload deployment and } \\
\text { drogue parachute applications. The development of encapsulation materials that will } \\
\text { activate/release their contents when subjected to specific stimuli such as a mechanical } \\
\text { pressure, a specific temperature, light of a specific wavelength, etc., would be very } \\
\text { useful operationally. This, coupled with the ability to produce capsules of various } \\
\text { diameters down to } 100 \text { microns, could considerably broaden the range of options for } \\
\text { delivery and deployment of numerous non-lethal payloads. The existence of such } \\
\text { materials will enable the development of common munitions capable of carrying } \\
\text { several types of non-lethal payloads fired from a large number of existing weapons } \\
\text { such as grenade launchers, mortars, field artillery, and aircraft ordnance. }\end{array}$ \\
\hline 5. Malodorants & $\begin{array}{l}\text { Malodorous substances can be very useful operationally in counter-personnel } \\
\text { applications where the minimum level of force is appropriate or as a first measure to } \\
\text { prevent escalation. By themselves, these extremely foul, putrid smelling substances } \\
\text { can be very effective first-level discriminators of motivation and intent. In } \\
\text { combination with other non-lethal technologies, such as bright light flashes and loud } \\
\text { explosive bangs, malodorants can effectively produce multi-sensory overload of } \\
\text { individuals and groups to temporarily incapacitate/distract them. The technology of } \\
\text { malodorous substances is mature. }\end{array}$ \\
\hline
\end{tabular}




\begin{tabular}{|c|c|}
\hline Technology & Rationale \\
\hline 6. Calmatives & $\begin{array}{l}\text { This technology was selected because of its very broad applicability and utility. } \\
\text { Sleep agents or calmatives that could render individuals incapable of continuing their } \\
\text { actions for various periods of time in a controllable fashion would be extremely } \\
\text { useful in a very large number of operational scenarios. To make them most useful, } \\
\text { calmative agents should be capable of being used in situations involving a mix people } \\
\text { of varying ages and physical characteristics. Consequently, the primary technical } \\
\text { challenge will be in developing agents that produce consistent, safe effects over broad } \\
\text { ranges of the human population, and be made relatively insensitive to dosage. } \\
\text { Additionally, mechanisms must be found to enable absorption into the body in a } \\
\text { variety of ways such as inhalation or through skin. Research is also needed to } \\
\text { accelerate the onset of the effects of these agents. This would enable the safe and } \\
\text { quick incapacitation of individuals in certain critical situations. The technical } \\
\text { challenge associated with this effort is deemed to be significant. }\end{array}$ \\
\hline $\begin{array}{l}\text { 7. High Power } \\
\text { Microwaves }\end{array}$ & Classified. \\
\hline 8. Rigid Foam & $\begin{array}{l}\text { Rigid foams provide significant utility for creating temporary barriers, particularly in } \\
\text { entryways, and for disabling the support functions of facility existence (i.e., power } \\
\text { distribution, communications, etc.). Additionally, they can be used to disable } \\
\text { vehicles and other equipment by jamming moving parts. This capability has } \\
\text { potentially broad application in the counter-materiel and counter capability areas. } \\
\text { Technical challenges still exist to reduce the hardening/curing time and to increase } \\
\text { structural strength. Additionally, other alternatives to deliver and deploy the foam } \\
\text { payloads, such as binary configurations, are needed to enable standoff and long-range } \\
\text { delivery when applicable. }\end{array}$ \\
\hline $\begin{array}{l}\text { 9. Tagging, } \\
\text { Tracking and } \\
\text { Locating }\end{array}$ & $\begin{array}{l}\text { The technology associated with luminous or covert dyes and paints is mature with the } \\
\text { majority of the effort required in developing delivery/deployment means (range and } \\
\text { non-disclosure) and integration into the necessary platforms. Significant work is } \\
\text { required to develop minute tagging devices capable of being tracked and located, as } \\
\text { well as their delivery/deployment means. }\end{array}$ \\
\hline 10. Nanoparticles & $\begin{array}{l}\text { Nanotechnology was chosen because of its significant potential contribution in } \\
\text { reducing the harmful effects of releases of chemical and biological agents. Although } \\
\text { early in development, the concept using reactive nanoparticles to decompose } \\
\text { chemical agents or to destructively absorb biological agents shows considerable } \\
\text { promise, and results of experimentation are very encouraging. Nanotechnology also } \\
\text { has significant potential of advancing materials development by enabling the } \\
\text { production of very high shear and tensile strength fibers that are extremely } \\
\text { lightweight. Such material could enable the development of new, highly effective } \\
\text { entanglement systems that can be used for both non-lethal counter-personnel and } \\
\text { counter-materiel applications. Technical challenges include the development and } \\
\text { testing of agents to counter the various threats, and developing the capability to } \\
\text { produce these substances in sufficient volume. }\end{array}$ \\
\hline
\end{tabular}




\begin{tabular}{|c|l|}
\hline Technology & \multicolumn{1}{c|}{ Rationale } \\
\hline $\begin{array}{l}\text { 11. Low Energy } \\
\text { Laser Scattering } \\
\text { and Dazzling }\end{array}$ & $\begin{array}{l}\text { The capability to temporarily obscure an adversary's vision can provide significant } \\
\text { military advantage in a number of situations. The use of low power, eye-safe lasers } \\
\text { against individuals for this purpose has been proven effective in evaluations } \\
\text { conducted during military operations. However, low-power laser technology also has } \\
\text { the potential to provide this capability against large groups yielding similar non-lethal } \\
\text { operational utility at a larger scale. This can be done by either directly illuminating } \\
\text { the adversary group with an eye-safe, broader laser beam or by illuminating an } \\
\text { external medium, such as an airborne aerosol cloud, resulting in the scattering of the } \\
\text { laser light and creating a "wall of light." Challenges exist in the accurate } \\
\text { characterization of effects on the human eye and in overcoming issues of public } \\
\text { perception associated with laser technology. }\end{array}$ \\
\hline 12. DF/HF Lasers & $\begin{array}{l}\text { Applications of pulsed Deuterium-Fluoride (DF) and Hydrogen-Fluoride (HF) laser } \\
\text { technology have direct applicability in the non-lethal counter-personnel area by } \\
\text { providing the unique capability to incapacitate individuals from standoff ranges of up } \\
\text { to 500 m. Mounted on a vehicle or eventually man-portable, these devices produce } \\
\text { pulsed energy projectiles that travel instantaneously and produce controllable effects. } \\
\text { Technical challenges include the development of a robust, practical field device, } \\
\text { successfully developing the capability to control the effects and characterizing the } \\
\text { human effects. }\end{array}$ \\
\hline
\end{tabular}

\section{Current Fielded Capabilities ${ }^{45}$}

Though still new, non-lethal weapons have already begun to make their way into the field. Currently, there are several non-lethal weapons that have been approved, operationalized, and added to the inventory for use by U.S. military forces. There are several non-lethal munitions in the inventory. Variants include 12-gauge shotgun shells equipped with "flashbang” projectiles designed to be fired over the heads of a violent or potentially violent crowd up to 100 meters away to deter or distract individuals and shells intended to stun or deter two or three people by delivering a strong blow to the body up to 30 meters. Similarly, a $40 \mathrm{~mm}$ round provides a capability to stun an individual with a sponge round up to 50 meters. A stingball/stun grenade is a commercial off-the-shelf item that operates like a standard hand grenade but dispenses rubber balls in a circular pattern of approximately 50 feet. It is designed to clear an area of a violent crowd. Oleoresin Capsicum (pepper spray) dispensers of different sizes for use on individuals or crowds are also available, as are caltrops, or tire spikes for disrupting vehicular movement. In addition to munitions, protection and training items make up "capability sets" designed to provide all the assets required for use in an environment 
requiring the use of non-lethal weapons. Protection items include batons, body, face, and shin shields, searchlights, disposable forearm and ankle cuffs, and bullhorns. Training items include a padded riot baton training suit, inert pepper spray dispensers, training stingball grenades, and a 12gauge training round. As can be seen, all of these weapons are shortrange, tactical devices geared toward force protection operations.

\section{Acquisition Programs}

In addition to the weapons already fielded, there are numerous other technologies, components, and systems that are in various phases of development under the Defense Acquisition System. These are listed in the sections that follow and are intended to give the reader a brief overview rather than an in-depth understanding of the kinds of non-lethal capabilities currently under research, development, and procurement. ${ }^{46}$

Three programs are currently in production to be fielded in the near future. These include a Modular Crowd Control Munition (a nonlethal variant of the current Claymore mine which propels hundreds of small rubber balls for use in crowd control), a 66mm Vehicle Launched NL Grenade (a short-range, indirect fire, crowd control/area denial nonlethal capability employing either a flash-bang device or 32-caliber rubber balls that can be employed from light vehicle), and a Portable Vehicle Arresting Barrier (PVAB) designed to stop a 7,500-pound vehicle traveling at speeds up to 45 miles per hour without causing permanent injury to the occupants. A $40 \mathrm{~mm}$ Non-Lethal Crowd Dispersal Cartridge (NLCDC) similar to the $40 \mathrm{~mm}$ round used against individuals is intended to disperse a group of people with rubber balls from a range of up to 30 meters. Finally, the Mobility Denial System (MDS) is a "non-hazardous chemical spray system that spreads a highly slippery, viscous gel to inhibit the movement of individuals or vehicles on treated surfaces such as asphalt, concrete, grass, and wood."47

\section{Concept Exploration Programs}

Researchers across the DOD have proposed many innovative concepts for achieving desirable non-lethal effects, but the technical viability of these solutions is not always obvious. Hence, as the name suggests, Concept Exploration Programs are designed to refine a proposed concept and to reduce the technical uncertainties. Several of these 
innovative concepts are being assessed to evaluate their viability for future military use. The first of these is the Clear Facilities (CFAC) program. Sponsored by the Marine Corps, the program's objective is to develop alternatives to assist operating forces in the clearing of buildings or structures (including ships or boats) without harming personnel, equipment or the structure. A second is the Non-Lethal Slippery Foam (NLSF) program, which is analyzing slippery foams to determine the degree and longevity of anti-traction capability on various surfaces. Both the Army and the Marine Corps are interested in the potential for NLSF to deny an area to pesonnel or vehicles. A third program, the Area Denial to Vehicles (AD-V) project managed by the U.S. Army, focuses on stopping vehicles in an urban or open environment, denying an area to land vehicles, and channelizing vehicles. A fourth program, Area Denial to Personnel (AD-P), is a U.S. Army project that explores alternatives to land mines. The Disable Displacement Vessels (DDV) program explores technologies to non-lethally disable vessels. Focusing on large displacement, diesel engine powered ships ranging from 150-600 feet in length, the DDV program explores methods of affecting a ship system or subsystem to cause the vessel to stop and yet be capable of quick reconstitution. A sixth program, the Crowd Control (CC) device sponsored by the Army, explores containing or stopping a crowd from advancing, dispersing a crowd at ranges up to 1,000 meters, and directing a crowd movement, separating belligerents, and isolating specific individuals within a crowd. Incapacitate Personnel (INCAP), a program under the auspices of the Marine Corps, seeks to develop capabilities to incapacitate individuals for the following tasks: distract an individual or group, seize an individual or group, render an individual or group unconscious, render an individual or group incapable of performing tasks, disorient an individual or group, facilitate deceptions and demonstrations, and facilitate the release of hostages.

\section{Component Advanced Development (CAD) Efforts}

A Component Advanced Development project is one in which a project leader has a concept for the needed capability but does not yet know the system architecture. The U.S. Marine Corps is sponsoring projects to develop two new non-lethal enabling technologies. One is an Anti-Traction Material (ATM) project aimed at developing water-cannonlike weapons that distribute slippery liquids or foams that preclude vehicle 
or personnel use of an area. The other project is a Clear Space Device (CSD), a grenade-like round that enables troops to shoot a number of different non-lethal substances into a building to clear it of its occupants.

\section{Pre-Milestone A Programs}

In the Defense Acquisition System, candidate technologies that meet certain criteria can be awarded Milestone $A$ approval. This award can lead to concept exploration or advanced component development, but more work is needed on key sub-systems or components before a system architecture can be determined and the technologies can be demonstrated in a relevant environment. ${ }^{48}$ Several Pre-Milestone A non-lethal programs are currently underway. One is the Running Gear Entanglement System, a rope device designed to stop fast-moving boats by floating in the water ahead of the target vessel and becoming entangled around the propeller or rudder as the vessel runs over it. A second is a pulsed energy projectile, a counter-personnel laser of which studied bio-effects include a disorienting "flash-bang," a sensation of pain, or incapacitation. A third involves a non-lethal round for the Objective Individual Combat Weapon (OICW). The OICW is a lightweight portable weapon capable of firing kinetic energy projectiles and an air-bursting fragmentation munition up to 1000 meters. ${ }^{49}$ The weapon is an advanced technology demonstrator currently under development with a fielding planned for 2005. The non-lethal side of the project exploits the ability of the OICW to airburst munitions at a precise location in space with non-lethal liquid, aerosol, powder or object munitions which can be used for either counter-personnel or countermateriel applications. ${ }^{50}$ The fifth weapon is a Non-Lethal Mortar Munition, an $81 \mathrm{~mm}$ round designed to deliver and dispense non-lethal payloads up to $1.5 \mathrm{~km}$. A sixth weapon is a non-lethal munition for the 40 mm Mk 19 Grenade Launcher, an air-cooled, $40 \mathrm{~mm}$ fully-automatic machine gun, firing $40 \mathrm{~mm}$ grenades at a rate of 325 to 375 per minute to a range of 1500 meters.

\section{Advanced Concept Technology Demonstrations}

The DOD initiated the Advanced Concept Technology Demonstration (ACTD) program in 1994 to answer a long-standing criticism that developing and building weapon and information systems was taking too long, costing too much, and not adequately involving those 
who ultimately use the equipment. The ACTD program allows military services or defense agencies to adapt new but mature technologies to build prototype equipment to meet a critical military need. The developed systems would then go to a unified command or service for evaluation in the field. After the two to four year ACTD project, the system would enter the formal acquisition process if larger quantities were needed. ${ }^{51}$

Two non-lethal demonstrations are currently underway or planned for the near term. The first is the Advanced Tactical Laser, which includes a laser, optics, and control systems enabling existing fire control systems on fixed and rotary wing aircraft to precisely direct laser fire on targets to disable them from 15 kilometers. ${ }^{52}$ The second, proposed for a FY 02 start is the Active Denial System. Active denial technology is a breakthrough non-lethal technology that uses millimeter-wave electromagnetic energy to stop, deter and turn back an advancing adversary from relatively long range. ${ }^{53}$ The current system is mounted on a Humvee, but other applications are envisioned.

\section{Technology Investment Projects}

The Joint Non-Lethal Weapons Program has an annual solicitation for new ideas. Selected projects are given funding for a maximum of two years to conduct a study or demonstrate a concept that provides a decision point for pursuing the technology more formally. The following ideas are currently being studied (studies have been recently completed for the fourth through tenth items):

- The Front-End Analysis of Riot Control Agents project seeks to identify feasible non-lethal chemical materials with minimal side effects for immobilizing adversaries in military and law enforcement scenarios.

- The Thermobaric Technology study determines the feasibility of using thermobaric technology, which produces light, overpressure, and heat, to incapacitate humans.

- The Veiling Glare Effects of Violet Laser Exposures in Humans project is an initial effort to evaluate the ability of a violet laser to create a veiling glare on isolated human lenses.

- The Odorous Substances project investigates odorants and their effects on behavior as a riot control means, as well as to clear facilities, deny an area, or as a taggant. 
- The Microencapsulation project identifies encapsulation techniques for anti-materiel and anti-personnel non-lethal weapons related to area denial and stopping vessels. Encapsulated techniques being pursued are those which will release and spread a variety of chemical payloads upon pressure, contact with water, or at a specific temperature.

- The Bio-Materials Survey project of the University of New Hampshire is gathering information on the physical properties of certain biomaterials applicable to non-lethal weapons, as well as on the organizations involved in their research or commercializing.

- The Overhead Liquid Dispersal System project studies the ability to rapidly disperse non-lethal chemical agents over large areas.

- The Taser Landmine project explores an alternative to personnel land mines - a device that fires small darts attached to wires that deliver an incapacitating electrical current.

- In the Non-Lethal Weapon Guided Projectile project, Raytheon is studying the feasibility of employing its Extended Range Guided Munition (ERGM) ${ }^{54}$ and other long range delivery vehicles such as mortars, shoulder launched weapons, artillery, missiles, guided bombs, and unmanned aerial vehicles to deliver non-lethal payloads (such as foams and irritants) for area denial and clearing facilities missions.

- The Non-Lethal Loitering Submunition project studies non-lethal payloads and a concept of operations for a loitering submunition.

\section{Additional Research Projects}

In addition to its nominal $\$ 25 \mathrm{M}$ annual budget, the Joint NonLethal Weapons Program received supplemental funding to conduct advanced prototype hardware, ruggedizing, packaging, and effects research in four areas. ${ }^{55}$ Directed energy research received funding for engineering and demonstration of launch and deployment options for nonlethal weapons used to repel belligerents. Navy force protection research aimed at evaluating technologies to stop small vessels at standoff distances was funded. Blunt impact and pulsed projectile research studies-nonlethal directed energy to deliver a controlled blunt impact on human targets at extended ranges, received funding. Finally, research into standoff delivery of non-lethal weapons seeks to identify specific delivery systems to deliver non-lethal payloads beyond 800 meters, for which there is no current capability, received supplemental funding. 


\section{Rejected Technologies}

There have already been some candidate non-lethal technologies that have been discarded due to technical problems. First, sticky foams were once seen as attractive candidates for both counter-personnel and counter-materiel applications. However, they have largely been dismissed due to concerns about the potential for accidental lethality (suffocating) and difficulty in removing the substances after use. ${ }^{56}$ A second rejected technology is infrasound, a technology designed to create disabling physical responses, such as nausea and incapacitating pain through the use of inaudible very low frequency (below $20 \mathrm{~Hz}$ ) noise. Anecdotal accounts exist of severe biological reactions due to this phenomenon. The Joint Non-Lethal Weapons Directorate sponsored extensive research in this area, but halted it in 1999 after the program failed to identify frequencies at which reliable, repeatable bio-effects could be produced. ${ }^{57}$

Having looked at the current state-of-the-art for non-lethal technology, we now turn our attention to some of the strategic issues that will need to be considered in assessing the future of these technologies as components of America's future military arsenal. 


\section{Strategic Advantages and Drawbacks of Non- Lethal Weapons}

Military theorist Carl Von Clausewitz spoke of the dominance of political considerations in the employment of military power. Clausewitz stated that "War should never be though of as something autonomous but always as an instrument of policy."58 Noted political and military thinker Colin Gray further argues that since war is "organized violence for political ends," then the tools of war are necessarily strategic: "It is inherent in their nature."59 Consequently, any proper discussion of the usefulness of a weapon type should center on its potential to elicit strategic effects - that is, how it might contribute to the successful achievement of political goals. With that said, one could make the case that some weapons are more strategic than others. The current stated focus of the DOD's non-lethal weapons program is for weapons and systems "designed primarily for use at the tactical level."60 As long as non-lethals remain as merely close-quarters, law-enforcement type tools comprising only a small fraction of the U.S. arsenal, it is difficult to foresee how they could routinely bring about strategic effects. The Joint Non-Lethal Weapons Directorate is considering weapons that directly influence operational or strategic targets. ${ }^{61}$ In fact, the JMAA study examined nearly 400 tasks listed in the Universal Joint Task List and service task lists that describe the capabilities required for warfighters to be able to successfully execute their assigned missions. The study found that an overwhelming majority of these tasks had either direct or indirect applicability for non-lethal weapons, even for tasks specified as "strategic national." "62 However, these strategic capabilities are only imagined at this point, and actual development efforts are still for tactical level weapons. The following discussion of the advantages and drawbacks of non-lethal weapons, therefore, looks to a future state of military affairs in which nonlethal weapons have reached a state of maturity and level of employment that makes their existence a substantial factor in war. It seeks to provide senior leaders with important issues to consider regarding these weapons in order to make informed decisions about whether their wide-scale development is an appropriate course of action. 


\section{Advantage \#1: Non-lethal weapons are consistent with American values (and that of our allies).}

A prerequisite for the fielding of any new weapon should be that its use is consistent with American values. U.S. Civil War General William Tecumseh Sherman observed that "war is hell," but the traditional (and prevailing) American belief is that human life is sacred and that pain and suffering should be limited, even on the battlefield, and especially in the case of non-combatants. This idea coincides with the internationally recognized concept of "right conduct in war," or jus in bello, which has three criteria. The first is that the immediate object of war is not to kill, but to restrain. Thus, soldiers who surrender may not be killed. The second criterion is that it is not legitimate to attack non-combatants directly or to use indiscriminate methods of warfare. Finally, causing unnecessary suffering is prohibited. ${ }^{63}$ These concepts originated with the religious culture of the Middle Ages and remain to this day the dominant military ethos of the Western world. $^{64}$ The interpretation of these principles has not always been easy (the morality of nuclear deterrence, for example), nor have they been perfectly applied (the My Lai massacre of the Vietnam War, for instance). Nevertheless, these ideals and principles have consistently guided American war experience. As George Schultz pointed out, America's strength ultimately derives not from our military or economic potency, but from our passionate commitment to ideals. $^{65}$ Consequently, recognition and observance of those principles is critical both to U.S. public support and the support of allies that share our values. Non-lethal weapons, which are specifically designed with the intent to minimize casualties, are self-evidently consistent with the Western concept of minimizing unnecessary suffering on the battlefield and among non-combatants.

\section{Advantage \#2: Non-Lethal Weapons can be a synergy-producing force multiplier.}

A second strategic advantage of non-lethal weapons is their potential for contributing synergies when they are employed with traditional lethal means. Synergy, the concept that the effects of coordinated forces can exceed the individual contributions of forces applied separately, is a fundamental of the military operational art as defined in joint doctrine. ${ }^{66}$ Examples of non-lethal means being used synergistically with lethal weapons may be as follows: an active tagger used to mark a target for later destruction, employing a counter-mobility 
weapon to demobilize assets in order to render them more vulnerable to lethal fires, or using a multi-sensory distraction device to provide tactical distraction and then bringing lethal force to bear. Combining non-lethal weapons with conventional weaponry, then, has the potential to provide warfighters with a key force multiplier. This is consistent with current DOD policy that "non-lethal weapons may be used in conjunction with lethal weapon systems to enhance the latter's effectiveness and efficiency in military operations. This shall apply across the range of military operations to include those situations where overwhelming force is employed."67 As mentioned earlier, current policy is that non-lethal weapons are not a guarantee against casualties. In fact, from the perspective of synergy, the availability of non-lethal technology can even potentially increase lethality — albeit to those upon which lethal effects are intended. The Council on Foreign Relations' 1999 Independent Task Force Report, Non-Lethal Technologies: Progress and Prospects, made just this point:

It is not the primary purpose of non-lethal weapons to prevent death or major injury to opposing troops. Instead, they are intended to increase the lethality of force used against combatants, while reducing death and injury among noncombatant civilians. For example, [non-lethal] weapons can prevent a crowd from approaching closely enough to be a serious threat to U.S. forces. They can also unmask snipers or other combatants in a crowd of civilians, opening a field for U.S. lethal fire. In short, [non-lethal weapons] are important because they permit military engagement at a lower level of violence. And in political terms, less violence equals more acceptability. ${ }^{68}$

\section{Advantage \#3: Non-Lethal weapons are precise-they put the "bottom rung on the ladder" of force escalation}

A third strategic advantage, and one of the greatest potential benefits of non-lethal weapons, is their ability to produce precision effects that are tailored to the needs of the warfighter. Joint Vision 2020 calls for the development of "full spectrum dominance" in which military operations are "persuasive in peace, decisive in war, preeminent in any form of conflict."69 Precision engagement is described as a key component of full spectrum dominance. It is in this area that non-lethal 
weapons provide the greatest potential contribution. Without the availability of non-lethal weapons, soldiers can be forced to choose between unacceptable alternative courses of action. For example, in human shield or crowd-control situations, commanders can face the choice of having to kill civilians in order to not lose an opportunity to destroy an important target or to protect their units in ambiguous urban combat settings. Consequently, the Joint Non-Lethal Weapons Program (JNLWP) FY00 Master Plan noted "deployments to Somalia, Haiti, Bosnia, and, most recently, Kosovo demonstrated the operational need for [non-lethal weapon] capabilities to supplement and/or augment lethal force in the battlespace."70 DOD policy on non-lethal weapons recognizes this potential to increase the options available to commanders: "Non-lethal weapons, doctrine, and concepts of operation shall be designed to reinforce deterrence and expand the range of options available to commanders"71 From this perspective, the Joint Non-Lethal Weapons Directorate sees non-lethal weapons as a means to "facilitate discrimination."72 Without access to non-lethal means, commanders have no intermediate choices on the continuum between "detect" and "destroy." Non-lethal weapons add "delay," “deny," and “defeat” as intermediate steps in the range of options available to the commander. ${ }^{73}$ If full spectrum dominance can be described as a ladder, non-lethal weapons put the bottom rung on that ladder by allowing warfighters' the potential to smoothly ratchet up the level of force as the situation warrants.

Advantage \#4: Non-lethal weapons can be the right weapon for the blurred environment between war and law enforcement

A fourth strategic advantage of non-lethal weapons is their unique ability to contribute to military operations at the low end of the spectrum-in situations that can look more like law enforcement activities than combat. U.S. armed forces are expected to perform operations across the spectrum, from military operations other than war to large scale combat operations. Future conflicts are likely to frequently enter that realm of warfare described by General Wesley Clark when he spoke of the 1999 Kosovo air campaign, "not quite war-not quite peace."74 Activities such as peace enforcement, counter-drug, and counter-terrorism operations are likely to create scenarios in which apprehending suspects and preserving evidence play a vital role. By their nature, non-lethal weapons minimize death and destruction and therefore are well suited to this 
function. Additionally, the reversibility of non-lethal weapons allows for recovery from, for example, a case of mistaken identity. Finally, nonlethal weapons improve the chances of apprehending suspects and bringing them to justice and may also allow soldiers to capture key evidence or enemy materiel that might, alternatively, have been destroyed by conventional weapons.

\section{Advantage \#5: Non-lethal weapons minimize opportunities for adversaries to provoke negative public opinion against our cause.}

A fifth strategic benefit comes in the area of public relations. Since military operations are carried out to accomplish political objectives, modern commanders are increasingly asked to keep one eye on the battlefield and the other on the newspaper headlines. Negative press, particularly the advertising of large numbers of civilian casualties, can have a direct and sizeable negative effect on our ability to conduct successful military operations. By reducing noncombatant casualties, nonlethal technology offers the ability to reduce these adverse effects.

\section{Advantage \#6: Non-lethal weapons limit collateral damage and post-war rebuilding and aid.}

A sixth strategic advantage of non-lethal weapons is their ability to reduce collateral damage. This is related to the public relations issue mentioned above since destruction of homes, hospitals, schools, and cultural and religious buildings produces some of the same kind of effects as images of children injured or killed by stray bombs. Another factor is also involved here-the economic costs of the destruction. Rebuilding the infrastructure of a nation destroyed by war has often been borne, either directly or indirectly, by the U.S. and her allies. Even in cases where we have not stepped in to rebuild, costs associated with refugees losing their homes or losing their ability to take part in meaningful economic activity can have an adverse effect on the world's economy, especially in our increasingly interdependent world. The potential indirect cost associated with the destruction of a country's economic base can obviously be substantial. Since poverty often breeds discontent, this can come back to haunt us. It is for this reason that DOD non-lethal policy states, "nonlethal weapons should also be designed to help decrease the post-conflict costs of reconstruction."75 


\section{Advantage \#7: Non-lethal weapons are potential WMD neutralizers}

A seventh and final strategic benefit of these weapons is their potential to neutralize Weapons of Mass Destruction (WMD). Operation Desert Storm highlighted the serious drawback of attempting to destroy WMD or WMD production facilities with conventional kinetic devicesnamely the risk of spreading poisonous materials that can harm friendly forces, civilians, or the environment. Seeking a technical solution to this problem, in 1999 the Air Force Research Laboratory Munitions Directorate issued a Program Research and Development Announcement (PRDA) seeking a contractor to work the problem. The program's objective was to produce an "Agent Defeat Warhead" capable of demonstrating "an ability to generate widespread damage within fixed ground targets associated with the development, production and storage of chemical and biological weapons, while limiting the potential for collateral damage (i.e., human casualties resulting from the unintentional release of [chemical and biological] agents beyond the confines of the target structure)...,"76 The proposal specifically called for lethal incendiary and low blast fragmenting warheads, but it also mentioned "neutralizing chemicals and other mechanisms" as candidate kill mechanisms. Though the laboratory did not receive an acceptable proposal by the PRDA closing date of 29 April 1999, the issue continues to receive considerable defense department attention. ${ }^{77}$ If a non-lethal weapon solution can be found, it would have the dual advantage of minimizing both the collateral human casualties and unintended damage to facilities. If preemptive strikes are envisioned, this feature will be particularly important, as it will reduce the negative reaction at home and abroad in what is likely to be a controversial action.

\section{Potential Drawbacks}

The advantages outlined above potentially offer significant enhancements to our ability to bring about desired political outcomes via military means. As mentioned earlier, there is a growing demand from combatant commanders for these capabilities. However, employment of these types of weapons does present numerous challenges and concerns as described below.

\section{Drawback \#1: Non-lethal weapons may produce unrealistic expectations.}


The first concern is that the weapons might present unrealistic expectations about the prospects for bloodless war. As mentioned earlier, part of the problem arises from the term "non-lethal" itself, leading some in the defense community to advocate adoption of substitute terms such as "less-lethal" or "sub-lethal effects weapons." An example of the trend toward unrealistic expectations can be seen in the current attitudes toward the use of precision munitions. Although weapons such as Global Positioning System (GPS) or laser-guided bombs make up a small fraction of the U.S. arsenal, dramatic footage of the accuracy and effects of these weapons has led to an expectation for extreme accuracy. For example, in the Gulf War, where precision munitions made up less than ten percent of the total weight of bombs dropped by the coalition, Benjamin Lambeth pointed out the following transcript:

...cockpit video images of LGBs [laser-guided bombs] homing with seemingly unerring accuracy down the air shaft of enemy bunkers were spellbinding to most observers. Yet thanks to that same seemingly unerring accuracy, such performance has since come to be expected by both political leaders and the public alike. ${ }^{78}$

Consequently, when any weapon, precision-guided or otherwise, misses its target and causes unintended death and destruction, the political fallout can be substantial. The diplomatic crisis caused by the inadvertent bombing of the Chinese Embassy in Kosovo provides one of the most glaring examples. As noted earlier in this paper, the DOD policy on nonlethal weapons represents an aggressive attempt to combat the false notion that non-lethal weapons will eliminate casualties by declaring,

Non-lethal weapons shall not be required to have a zero probability of producing fatalities or permanent injuries. However, while complete avoidance of these effects is not guaranteed or expected, when properly employed, nonlethal weapons should significantly reduce them as compared with physically destroying the same target. ${ }^{79}$

Incidentally, the JMAA report recommends employing "perception management" to counter false impressions about the intent and anticipated results of these weapons. ${ }^{80}$ 
A related yet flip-side concern is also possible. There is a potential for negative public reaction to U.S. forces employing lethal force when non-lethal means may be available. Martin Stanton foresees scenarios in which an adversary manufactures an incident specifically for the purpose of causing casualties that can be leveraged for political gain. ${ }^{81}$ In the media examination that follows the event, the rioters could be described as "peaceful protesters," and considerable speculation could occur as to why rubber bullets or other non-lethal means were not used. The bottom line is that aggressive efforts will be needed to combat these potentially dire political attitudes and effects.

\section{Drawback \#2: Non-lethal weapons offer the potential for the enemy to fight again.}

A second concern regarding non-lethal weapons is the potential for opposing forces to return to the battlefield to fight again. Mercy on the battlefield sometimes backfires. For example, some of the prisoners paroled by General Grant at Vicksburg during the U.S. Civil War fought him again in later battles. ${ }^{82}$ Clausewitz warned that, in general, the enemy's “fighting forces must be destroyed: that is, they must be put in such a condition that they can no longer carry on the fight." 83 This is an issue that must be considered if increasing reliance on non-lethal weapons becomes a reality.

\section{Drawback \#3: Non-lethal weapons can diminish deterrence.}

A third concern is that the deterrent value of military force may be diminished. One way of preventing war is by "rendering the use of arms so unattractive that a nation would rather tolerate existing conflicts and frustrations than start a war." 84 Although DOD policy states, "non-lethal weapons, doctrine, and concepts of operation shall be designed to reinforce deterrence and expand the range of options available to commanders," the perception that the U.S. is hesitant to use lethal force could embolden a potential adversary. For example, terrorist mastermind Osama bin Laden has stated,

We think that the United States is very much weaker than Russia. Based on the reports we received from our brothers who participated in jihad in Somalia, we learned that they saw the weakness, frailty, and cowardice of U.S. troops. Only 80 U.S. troops were killed. Nonetheless, they fled in 
the heart of darkness, frustrated, after they had caused great commotion about the new world order. ${ }^{85}$

The perception that the U.S. lacks resolve can lead to conflict that otherwise would be deterred. Clausewitz warns, "Kind-hearted people might of course think there is some ingenious way to disarm or defeat an enemy without too much bloodshed, and might imagine that this is the true goal of the art of war. Pleasant as it sounds, it is a fallacy that must be exposed: war is such a dangerous business that the mistakes from kindness are the very worst.”86 Martin Stanton puts it this way:

Far from strengthening our position in these places, nonlethal weapons further convey to our potential adversaries that we are too squeamish to hurt even our enemies, let alone take casualties ourselves. Arrayed against people who have nothing to lose, we are saying in effect that we will go to extraordinary lengths to keep from harming them. This conveys neither strength nor resolve, the two traits that gain the most respect in the anarchic world. The new non-lethal technologies are the epitome of "tepid shows of force. ${ }^{87}$

\section{Drawback \#4: Non-lethal weapons may inhibit our ability to overcome our adversary's hostile will.}

A fourth concern is that use of non-lethal weapons may unnecessarily extend a war because the enemy's hostile will has not been overcome. Clausewitz reminds us that men fight out of two motivations: "hostile feelings and hostile intentions." 88 Short of removing an adversary's ability to resist, overcoming these hostilities is an important factor in bringing a conflict to a conclusion. Removing the cost of war (that is, the destruction of lives and property) could, therefore, remove an important ingredient in bringing war to a conclusion. This is not always the case. In fact, a war may be prolonged because the public or government may believe that the outcome of the war must justify past sacrifices. ${ }^{89}$ However, this potential adverse effect of the use of non-lethal weapons must be considered. In contemplating his famous raiding march from Atlanta to Savannah, General William Tecumseh Sherman declared, "I would not coax or even meet them half way but make them so sick of war that generations would pass before they would again appeal to it...."90 That statement may clash with modern sensibilities, but it illustrates the 
idea that wars sometimes end only when nations reach a threshold of pain sufficient to cause them to desire to bring the war to an end.

\section{Drawback \#5: Non-lethal weapons may proliferate and be used against} us.

A fifth concern relates to proliferation - the potential that as these non-lethal technologies proliferate, they could be used against us. This is something that must be considered in the development of any new weapon. However, these concerns are mitigated by two factors. One is that technologies don't drive decisive effects on the battlefield without being integrated into weapon systems and also having the doctrine and training necessary to make their use effective. The other is that the U.S. has developed and maintained decisive military power, not only by merely developing technological advancements, but also by continuing to invest in technologies to stay ahead of competitors and adversaries. The concern over proliferation does, however, point to the need to consider defenses against these weapons should they fall into the wrong hands. A related concern is that an adversary might use them as a torture device, since many of them can inflict pain without necessarily causing permanent disfiguring or dismemberment. This may be an unwarranted fear, however, since numerous ways already exist to torture prisoners without permanently injuring them. ${ }^{91}$ Another concern is that in the hands of an unscrupulous police force these weapons could provide a tyrannical leader with a tool to oppress his or her own people. Again, however, many of these leaders have already demonstrated a willingness to commit even genocide against their own people; providing such a regime a non-lethal weapon would seem to be a far less evil.

\section{Drawback \#6: The availability of non-lethal technology may lure adventurism.}

A sixth possible criticism of reliance on non-lethal weapons is that they may make us more prone to commit to military action that may have negative economic or diplomatic consequences or may escalate to become an unintended major conflict. The argument goes that since bloodshed and destruction can be greatly reduced with these weapons, we may be tempted to intervene at an earlier point. ${ }^{92}$ Two counter points offset this concern. One is that if political leaders are made aware of the potential for this adverse consequence, they will be in a position to make an informed decision about whether to commit forces. This fear would only seem 
warranted if leaders have unrealistic expectations about these weapons, as mentioned in drawback number one above. Current DOD policy makes it clear that "in all cases, the United States retains the option for immediate use of lethal weapons, when appropriate, consistent with international law."93 A second counter to this concern is there may be situations in which the U.S. has a very real desire to get involved in a volatile situation but fails to do so because it lacks the expanded range of options provided by non-lethal weapons.

As the preceding discussion shows, there are no simple answers when it comes to non-lethal weapons. They may provide revolutionary new capabilities, enabling the precision application of force to bring about positive political outcomes with minimal injury, death, and destruction. On the other hand, they may fuel unrealistic expectations, cause us to commit to action prematurely, or even prolong a war. A careful and continuous assessment of the strategic advantages and disadvantages of non-lethal weapons is needed as we move along a path toward making them a more important part of our military forces structure. 
36...Non-Lethal Weapons 


\section{Outstanding Issues}

The preceding discussion attempts to anticipate the potential strategic effects, both positive and negative, of non-lethal technology. Before widespread use of these weapons can be realized, however, there are a number of issues that need to be addressed. Legal and ethical concerns as well as operational issues will need to be dealt with thoroughly. Efforts to sort out these issues in the joint community are accelerating; however, substantial work still remains to take these weapons beyond what the Director of the Joint Non-Lethal Weapons Directorate, Marine Colonel George Fenton, describes as the "rubber bullet modality." "T4 The following sections will describe the challenges in bringing these weapons to fruition.

\section{Legal and Ethical concerns}

Legal and ethical issues are central to the effort to develop nonlethal weapons. The U.S. Constitution enshrines the principle that, along with the Constitution and domestic law, international law agreed to by treaty "shall be the supreme law of the land." "95 For this reason, DOD policy requires that non-lethal weapons be consistent with international law. $^{96}$ It is the view of the Joint Non-Lethal Weapons Directorate's JMAA panel that existing treaties NOT be modified to accommodate nonlethal weapons. ${ }^{97}$ A counter view is that all laws need to be continually adjusted to maintain relevance to new situations. Laws that perpetuate human suffering or ones that are inconsistent with the shared values of the U.S and her international allies should be reexamined. One might even skeptically opine, as an international diplomat once did, “international law is the law which the wicked do not obey and which the righteous do not enforce."98 It is an irony that legal constraints on these types of weapons, which by their very nature are intended to minimize unnecessary loss of life and destruction of property, may cause commanders to select more lethal forms of warfare.

Arguments on whether these laws should be changed notwithstanding, the current laws must be adequately addressed. There are two broad areas of international law dealing with the acceptability of a weapon or method of warfare. The first is the Law of Armed Conflict, the guiding principle of which is that of humanity, which demands that 
combatants and non-combatants should not be subject to unnecessary suffering. Under this broad umbrella is the more specific concept of proportionality, which states that any suffering caused must be weighed against the military necessity of the action. ${ }^{99}$ The second and related area of international law is the Principle Governing Weapons, which includes the following three principles. ${ }^{100}$ The first is the unnecessary suffering principle, which prohibits employment of "arms, projectiles, or material calculated to cause unnecessary suffering." ${ }^{01}$ The second, the discrimination principle, holds that weapons must be directed against military objectives. It prohibits attacks against targets in which the anticipated civilian injuries or death or destruction of property exceeds the anticipated military advantage of the attack. ${ }^{102}$ A third concept, known as the treachery or perfidy principle limits the perfidious use of weapons that are inherently treacherous. ${ }^{103}$

In addition, generally accepted principles of acceptable conduct in war are captured in Protocol I of Geneva Conventions Art I (2) of 1977:

In cases not covered by this Protocol or by other international agreements, civilians and combatants remain under the protection and authority of the principles of international law derived from established custom, from the principles of humanity and from the dictates of public conscience.

In addition to these general principles, other treaties and conventions limiting specific types of weapons apply also to the non-lethal varieties. Table 4 is a list of declarations and conventions with relevance to nonlethal weapons.

DOD policy dictates that every new weapon will undergo legal reviews during several phases of the acquisition process to ensure that the weapon or weapon system complies with all applicable treaties, international law, and the law of armed conflict. ${ }^{104}$ Service instructions implement the DOD instruction. For example, Air Force Instruction 51402: Weapons Review states that the Judge Advocate General will ensure all weapons being "developed, bought, built, or otherwise acquired, and those modified by the Air Force" are reviewed for legality under international law prior to their use in a conflict. ${ }^{105}$ The Office of the Assistant Secretary of the Air Force for Acquisition (SAF/AQ) also carries responsibilities for ensuring legality of all weapons. ${ }^{106}$ 


\section{Table 4: Summary of Treaties, Laws, and Regulations Concerning Non-Lethal Weapons ${ }^{107}$}

\section{Treaties}

1. Convention (IV) Respecting the Laws and Customs of War on Land and Its Annex: Regulations Concerning the Laws and Customs of War on Land. The Hague, 18 October 1907.

2. Protocol for the Prohibition of the Use of Asphyxiating, Poisonous or Other Gases, and of Bacteriological Methods of Warfare. Geneva, 17 June 1925.

3. Geneva Convention (I) for the Amelioration of the Condition of the Wounded and Sick in the Armed Forces in the Field. Geneva, 12 August 1949.

4. Geneva Convention (II) for the Amelioration of the Condition of the Wounded, Sick and Shipwrecked Members of Armed Forces at Sea. Geneva, 12 August 1949.

5. Geneva Convention (III) Relative to the Treatment of Prisoners of War. Geneva, 12 August 1949.

6. Geneva Convention (IV) Relative to the Protection of Civilian Persons in Time of War. Geneva, 12 August 1949.

7. Convention on the Prohibition of the Development, Production and Stockpiling of Bacteriological (Biological) and Toxin Weapons and on their Destruction. Opened for Signature at London, Moscow and Washington. 10 April 1972.

8. Convention on the Prohibition of Military or any Hostile Use of Environmental Modification Techniques. 10 December 1976.

9. Protocol Additional to the Geneva Conventions of 12 August 1949, and relating to the Protection of Victims of International Armed Conflicts (Protocol I), 8 June 1977. [The United States is not a party to this Protocol. Many of its provisions are acceptable to us as customary international law, but we strongly object to several. Most of our allies have ratified this Protocol.]

10. Protocol Additional to the Geneva Conventions of 12 August 1949, and relating to the Protection of Victims of Non-International Armed Conflicts (Protocol II), 8 June 1977. [The United States is not a party to this Protocol, but we deem most of it as customary international law. President Reagan forwarded it to the Senate for ratification, but the Senate failed to act on it.]

11. United Nations Convention on Prohibitions or Restrictions on the Use of Certain Conventional Weapons Which May be Deemed to be Excessively Injurious or to Have Indiscriminate Effects (UNCCW). Geneva, 10 October 1980.

12. UNCCW Protocol on Non-Detectable Fragments (Protocol I). Geneva, 10 October 1980.

13. UNCCW Protocol on Prohibitions or Restrictions on the Use of Mines, Booby-Traps and Other Devices (Protocol II). Geneva, 10 October 1980.

14. UNCCW Protocol on Prohibitions or Restrictions on the Use of Incendiary Weapons (Protocol III). Geneva, 10 October 1980. [This Protocol was forwarded to the Senate for ratification. If ratified, it will be accompanied with reservations.]

15. Convention on the Prohibition of the Development, Production, Stockpiling and Use of Chemical Weapons and on Their Destruction. Paris, 13 January 1993. 


\section{Treaties (continued)}

16. UNCCW Protocol on Blinding Laser Weapons (Protocol IV to the 1980 Convention), 13 October 1995. [This Protocol was forwarded to the Senate for ratification.]

17. UNCCW Protocol on Prohibitions or Restrictions on the Use of Mines, Booby-Traps and Other Devices as Amended on 3 May 1996 (Amended Mines Protocol). [This Protocol was forwarded to the Senate for ratification in Jan 97 along with Protocols III and IV. It has been ratified, while the Senate has not yet acted on the other two.]

18. Convention on the Prohibition of the Use, Stockpiling, Production and Transfer of Anti-Personnel Mines and on their Destruction, 18 September 1997. [The United States is not a party to this Convention, but the vast majority of our allies have ratified it.]

19. Rome Statute of the International Criminal Court, 17 July 1998. [The United States is not a party to this Treaty, but the Treaty will allow the ICC to obtain jurisdiction over non-Party nations. The Treaty will enter into force once 60 nations have ratified it. So far, 30 nations have done so.]

\section{Domestic Law}

1. Biological Weapons Anti-terrorism Act of 1989, 18 U.S.C. § 175.

2. Chemical Weapons Anti-terrorism Act, 18 U.S.C. § 229 (1998).

3. Defense Authorization Act of 1996, § 219.

\section{Policies and Regulations}

1. DODD 3000.3, Policy for Non-Lethal Weapons, 9 July 1996.

2. DOD Instruction 5000.2, Operation of the Defense Acquisition System, 23 October 2000.

3. DODD 5100.77, DOD Law of War Program, 9 December 1998.

4. DODD 3216.2, Protection of Human Subjects in DOD-Supported Research.

5. DOD Policy on Blinding Lasers, 17 January 1997.

6. Department of Health and Human Services Regulation, "Protection of Human Subjects,” 45 CFR 46, 1 October 1999.

The Department of the Navy Judge Advocate General (JAG) has completed final legal reviews on several non-lethal weapons, including stinger grenades, 12-gauge shotgun bean bag/rubber pellet/wood baton rounds, $40 \mathrm{~mm}$ rubber pellets, foam rubber, bean bag, and wood baton 
rounds, sticky restraining foam, barrier foam, and a $40 \mathrm{~mm}$ practice M781 round modified with foam rubber projectile. ${ }^{108}$ The Department of the Navy JAG also performs preliminary legal reviews of candidate technologies before extensive research and development takes place. ${ }^{109}$ Several other candidate non-lethal weapons have received preliminary approval. Anti-personnel technologies passing preliminary legal review include gastrointestinal convulsives, calmative agents, sticky foam, aqueous foam, adhesives, malodorous agents, Oleoresin Capsicum (OC) cayenne pepper spray, smokes and fogs, riot control agents (CS \& $\mathrm{CN}$ ), slick coatings and superlubricants. Anti-material technologies receiving preliminary legal approval include viscosity/surface polymerization agents, corrosive agents, caustic agents, embrittling agents, depolymerization agents, combustion modifiers, sticky foam, adhesives, microbes, and slick coatings and superlubricants. Calmative and gastrointestinal convulsives, if classified as riot control agents (and not used on combatants), can be acceptable within the context of the Biological Weapons Convention. ${ }^{110}$ Once these technologies evolve into actual weapons and weapon systems, the host service Judge Advocate General will then review and analyze them in light of their toxic properties and compliance with international laws and treaties as well as domestic restrictions before granting final approval or rejection.

One aspect of the legal discussion regarding non-lethal weapons is the meaning of the term weapon. Oddly enough, no official definition is given for the term in official DOD publications, and there are many nonlethal products (for example, the ancillary technology items given in Table 2 above) that would probably not be considered weapons. As a result, their employment may not face the same policy restrictions as systems classified as bona fide weapons. Hence, the JMAA report recommends developing a definition of weapon that allows for the distinction between non-lethal weapons and other non-lethal capabilities. ${ }^{111}$

\section{Chemical Weapons}

The Chemical Warfare Convention (CWC), to which the U.S. is a party, is one of the most important international agreements relating to non-lethal weapons. As was seen previously, many candidate weapons are based on chemicals. A special case that illustrates the ability of the CWC to restrict chemical weapon development and use is riot control agents. The CWC specifically prohibits the use of riot control agents "as a method 
of warfare." that can "produce sensory irritation or disabling physical effects in humans, which disappear within a short time following termination of exposure."113 The convention recognizes "law enforcement including domestic riot control purposes” as specifically not prohibited, and U.S. policy has been to use these agents for law enforcement purposes, in support of rear area operations, against rioting prisoners of war, to protect convoys and nuclear weapons, and during search and rescue operations. ${ }^{114}$ Though the U.S. Senate ratified the convention, their concern over its potential to restrict legitimate uses of riot control agents in peacekeeping operations led to the Senate requiring the President to certify that riot control agents may be used in peacekeeping operations. On 25 April 1997, President Clinton certified to the Congress that the U.S. is not restricted in its use of riot control agents in "various peacetime and peacekeeping operations" and informed the U.N. Secretary-General that the United States would become an original party to the convention by ratifying the treaty before its 29 April 1997 entry-into-force deadline (180 days after the 65th signatory deposited its instrument of ratification). ${ }^{115}$

\section{Biological Weapons}

The Biological Weapons Convention, signed by the U.S. in 1972 and ratified in 1975, is even more restrictive than the Chemical Weapons Convention. The parties to the convention undertake "never in any circumstances" to "develop, produce, stockpile or otherwise acquire or retain...microbial or other biological agents, or toxins whatever their origin or method of production, of types and in quantities that have no justification for prophylactic, protective or other peaceful purposes.”116 Microbes represent the only technology undergoing a legal review by the Navy JAG that did not receive approval for development since this category of weapon violates the Biological Weapons Convention. Though a signatory to the convention, the U.S. has resisted recent attempts to institute compliance mechanisms. At a July 2001 meeting of the Ad Hoc Group negotiating the final text of the verification protocol that would attempt to strengthened the Biological Weapons Convention, U.S. Ambassador Donald Mahley announced that the U.S. would not support a draft protocol to the convention because it "would not improve our ability to verify compliance with the treaty's global ban on biological weapons and would put national security and confidential business information at 
risk."117 It was also announced that the U.S. "would pursue alternative ways to enforce the BWC that do not pose risks for U.S. bio-warfare defense preparations, sensitive commercial information and multilateral export regimes." Though the debate will continue regarding how to be enforce the treaty, it is clear that it will be a significant factor in future efforts to develop new non-lethal weapons.

\section{Environmental concerns}

Environmental concerns are also an issue. Though environmental issues have historically taken a backseat to winning a war, compliance with environmental law, both international and domestic, poses restrictions to U.S. efforts to develop certain classes of non-lethal weapons. ${ }^{118}$ For example, when sticky foam was being considered, it was deemed acceptable under the Chemical Weapons Convention since the foam disables through its binding property rather than its toxicity. However, an environmental issue was raised related to the Montreal Protocol on Substances that Deplete the Ozone Layer since Freon-12 (an ingredient comprising approximately 30\% of sticky foam) was banned after 31 December 1995 by the Clean Air Act (which implements the Montreal Protocol). ${ }^{119}$ Environmental law will continue to be a constraint in the further development of non-lethal technology.

\section{Operational concerns}

In addition to the legal concerns, there are numerous operational issues that will need to be carefully considered before fielding non-lethal weapons. A detailed explanation of these issues is beyond the scope of this paper; however, a brief outline of some of the operational challenges facing the development and fielding of non-lethal weapons is provided. These issues were explored as part of the effort to produce the JMAA, and they continue to be an integral part of the Joint Non-Lethal Weapons Directorate's endeavors. First, with each of the weapons, tactical issues must be resolved. As just one example, Martin Stanton has pointed out that anti-traction technology it is a double-edged sword. ${ }^{120}$ Though turning a road into a skating rink could be a very effective way of slowing down rioters or enemy combatants, it has the same effect on friendly forces that intend to use the same street. Also, anti-traction material would be relatively ineffective on dirt roads. The bottom line is that the 
risk to friendly forces must be considered. Second, a determination needs to be made as to whether specialized non-lethal weapons or multi-purpose weapons are most appropriate. One point of view is that having visible, non-lethal-only weapons reduces the chances of escalation where use of lethal force is undesirable (it also reduces the logistics and training complications, which can be another major concern). The reverse argument is that taking away the option to go lethal also reduces deterrence. $^{121}$ A related concern is what to do about a lethal response if friendly forces have only non-lethal weapons readily available. A third operational issue relates to rules of engagement for non-lethal weapons. The Policy Working Group of the JMAA panel noted that in past operations, "authorization to use non-lethal capabilities has often been coincident with authorization to use lethal force."122 The simplicity of this policy, however, reduced some of the flexibility gained by the presence of non-lethal weapons. By treating non-lethal weapons exactly the same as their lethal counterparts, much of the unique potential of non-lethal weapons to prevent or reduce escalation and to provide the commander in the field with a "set of tools between a warning and the actual use of force" is lost. ${ }^{123}$ A related concern is whether non-combatants can be targeted with non-lethal weapons, for example, in the case of "human shields" being used to protect an otherwise viable military target. Future rules of engagement involving non-lethal weapons need to carefully weigh the unique capabilities of these weapons. Interoperability with coalition members is a fourth operational issue that needs to be addressed. U.S. defense policy emphasizes going to war as part of a multinational effort. Consequently, interoperability of non-lethal weapon systems with coalition or alliance partners needs to be considered. Also, coalition members may offer different interpretations to international law relating to these weapons or have different doctrines regarding their use, which could further complicate the situation. A fifth issue is the cost of these weapons. The Programs and Resources Working Group of the JMAA panel was tasked to examine current and future "resource trends and forecasts and prepare resource assessments."124 The group assessed eight representative systems to obtain rough cost estimates for research and development, acquisition, and procurement of these non-lethal systems. Total system cost estimates ranged from approximately $\$ 100 \mathrm{M}$ for an indirect guided (non-line-of-sight) system to deliver nanoparticles to neutralize a biological or chemical agent WMD to approximately $\$ 11.5 \mathrm{~B}$ for a longrange system to deliver a directed energy device via proximity fusing 
technology to disable a vehicle. ${ }^{125}$ What were even more striking than the steep price tags for these weapons were the comments the resources group had regarding the overarching and specific constraints of non-lethal weapons. Among the constraints the group highlighted were the following:

- POM initiatives of multiple services would be required to efficiently fund these weapons.

- Testing and evaluation requirements of non-lethal technology represent significant investments.

- Non-lethal weapons are not seen as a core competency of military forces and may not compete well for resources.

- Current funding is inadequate for full development of state-of-the-art technical concepts and the necessary doctrinal evaluations of such concepts.

- No avenue currently exists for the joint funding of a dedicated, focused science and technology effort for non-lethal capabilities.

- There are no tools available to fully evaluate human effects and specific operational concepts, and funding constraints do not give adequate improvement in this area without heavily cutting into acquisition efforts.

- Current core funding for the Joint Non-Lethal Weapons Program of approximately $\$ 24 \mathrm{M}$ is not adequate to address the needs for development of future technologies. ${ }^{126}$

The 2001 QDR report calls for “selectively recapitalizing legacy forces to meet near-term challenges and to provide near-term readiness."127 Perhaps refitting certain legacy systems with non-lethal payloads offers at least a partial answer to these substantial funding challenges. A final operational concern is the need to have confidence that these weapons are going to achieve their advertised effects. This is a special concern for anti-personnel non-lethal weapons, as human effects can be very difficult to predict with precision. This is an area for which the JMAA panel urges aggressive action, as current human effects models are not adequate to give confidence in repeatable results. ${ }^{128}$ Clearly, a significant number of operational issues will need to be considered in developing a major non-lethal capability. 
46...Non-Lethal Weapons 


\section{Non-Lethal Weapons in the War on Terrorism}

As mentioned earlier, the events of September 11, 2001, have forced the defense community to rethink the nature of the threats facing the United States and the means for defending against future attacks. The Secretary of Defense's 2001 Quadrennial Defense Review confirmed this new priority. The report begins "On September 11, 2001, the United States came under vicious, bloody attack," and the attack is mentioned thereafter no less than fifteen times. Similarly, the general topic of terrorism receives attention thirty-two times in the short report. Since the campaign against terrorism is likely to be an important task assigned the U.S. military for the foreseeable future, it is appropriate to consider how non-lethal weapons might contribute to the success of that campaign. The Joint Non-Lethal Weapons Directorate's JMAA panel concludes that nonlethal weapons can contribute capabilities across the spectrum, from Military Operations Other Than War to Major Theater Wars. ${ }^{129}$ An important question to reflect on, however, is whether non-lethal technologies are particularly suited to the specific operating environments likely to be encountered in combating terrorism.

In order to judge the value of non-lethal weapons in this regard, one must first determine the salient characteristics of the operating environment. Title 22 of the United States Code defines terrorism as "premeditated, politically motivated violence perpetrated against noncombatant targets by sub-national group or clandestine agents," usually intended to influence an audience." ${ }^{\text {"30 }}$ According to the U.S. Department of State report "Patterns of Global Terrorism-2000," U.S. counter-terrorism policy is first, to make no concessions to terrorists and strike no deals; second, to bring terrorists to justice for their crimes; third, to isolate and apply pressure on states that sponsor terrorism to force them to change their behavior; and fourth, to bolster the counter-terrorism capabilities of those countries that work with the U.S. and require assistance. $^{131}$ That short statement provides a great deal of information regarding what future operations against global terrorism might look like. Although one military campaign is too small a sample set to ascertain a pattern, the actions against Afghanistan provide other important clues about how the more widespread war against terrorism may progress. ENDURING FREEDOM began with conventional bombing of Taliban 
command and control, air defense systems, and Taliban air assets, followed by aerial attacks on Taliban ground forces. The next major feature placed heavy emphasis on Special Forces to locate and root out terrorist operatives, representing another pattern that is likely to be a central feature of the ongoing counter-terrorist operations. As President Bush proclaimed in his September 20, 2001 address to the joint session of Congress, "Our war on terror begins with al-Qaida, but it does not end there. It will not end until every terrorist group of global reach has been found, stopped, and defeated." He stated further that this war would not look like the war against Iraq a decade ago or like the air war in Kosovo. Rather, the response would involve "far more than instant retaliation and isolated strikes. Americans should not expect one battle, but a lengthy campaign, unlike any other we have seen. It may include dramatic strikes, visible on television, and covert operations, secret even in success." Mr. Bush laid out that U.S. objectives were not only to "starve terrorists of funding, turn one against another, drive them from place to place, until there is no refuge or rest," but also to "pursue nations that provide aid or safe haven to terrorism."132 A final characteristic of the war against terrorism involves the nature of terrorism itself. Specifically, it is highly political in nature. As discussed earlier, all war is dominated by political considerations. With terrorism, policy issues are even more pronounced. The reason for this is that the materiel effects of terrorism (with the obvious exception of cases where weapons of mass destruction are involved) are small compared to their political effects. Take as just one example the conflict between Israel and the Palestinians. A suicide bombing (or the retaliatory strike that ensues) that kills a dozen people makes headlines around the world. As horrible as these events are in terms of the pain and heartache they cause the individuals and families affected, the political effects they engender go far beyond the physical effects of the attacks. To illustrate, consider the fact that twice as many Israelis died in automobile accidents than died from terrorist attacks during 2001. ${ }^{133}$ Terrorist attacks, unlike conventional war, are not able to directly threaten state survival. Since the war on terrorism is more sensitive to political issues, then the ability of non-lethal weapons to affect political outcomes takes on a heightened importance. This discussion leads us to the point where we can draw some conclusions about the key aspects of the war on terrorism. To summarize what future military counter-terrorism operations might involve from the counter-terrorism 
policy statement, the war in Afghanistan, and President Bush's statements, the following military tasks or operations seem likely:

- Special Operations Forces used synergistically with conventional forces such as air power

- "Bringing terrorists to justice” for their crimes

- Isolating and applying pressure on states that sponsor terrorism

- Bolstering the counter-terrorism capabilities of partner nations

- Protracted operations

- Emphasis on political factors

Given these characteristics, it would be helpful to consider whether any of the characteristics of non-lethal weapons presented in the previous section hold special relevance in the war on terrorism. To reiterate, this paper is not focused on tactical issues. Rather, it concerns itself with the strategic issues of non-lethal weapons. Though the tactical advantages may be sizeable (for example, an effective non-lethal method of subduing an airline hijacker may prove to be of great importance), that analysis will be left to others. Following the same topic areas discussed in the previous section, Tables 5 and 6 below shows suggested strategic advantages and disadvantages of non-lethal weapons for counter-terrorism operations.

As seen from the analysis in Tables 5 and 6 , the operational realities and highly political nature of the war on terrorism suggests that non-lethal weapons may indeed be of special utility. Both the positive and negative potentials of these weapons seem to be magnified when applied to counter-terrorism operations. However, the advantages nonlethal weapons offer at the strategic level seem to outweigh the negatives and make them a particularly valuable tool for the war against terrorism. 
Table 5: Advantages of Non-Lethal Weapons Against Terrorists

\begin{tabular}{|c|c|}
\hline Advantage & Relevance to Counter-Terrorism Operations \\
\hline $\begin{array}{l}\text { Consistent with American } \\
\text { values (and that of our allies) }\end{array}$ & $\begin{array}{l}\text { Especially relevant. Public support must be } \\
\text { maintained for campaign that could be protracted. } \\
\text { Perceptions that use of military force is consistent } \\
\text { with American values will help maintain that support. }\end{array}$ \\
\hline Force Multiplier_-Synergy & $\begin{array}{l}\text { Especially relevant. Synergistic use of airpower and } \\
\text { Special Forces has already proven to be effective. } \\
\text { Creative blend of traditional lethal and non-lethal } \\
\text { might produce similar positive, asymmetric results. }\end{array}$ \\
\hline $\begin{array}{l}\text { Precision Weapon-Putting } \\
\text { the bottom rung on the ladder }\end{array}$ & $\begin{array}{l}\text { Especially relevant. Gives commanders the potential } \\
\text { to apply force very precisely, discriminating between } \\
\text { known terrorists and bystanders. }\end{array}$ \\
\hline $\begin{array}{l}\text { The Right Weapon for } \\
\text { Blurred Environment } \\
\text { between War and Law } \\
\text { Enforcement }\end{array}$ & $\begin{array}{l}\text { Especially relevant. Operations may include activities } \\
\text { such as apprehending terrorists to be tried in civil or } \\
\text { military courts. As noted earlier, the reversibility of } \\
\text { non-lethal weapons allows for recovering from a case } \\
\text { of mistaken identity. This is particularly applicable to } \\
\text { counter-terrorism, where forces are likely to possess } \\
\text { incomplete knowledge of who the enemy is. Non- } \\
\text { lethal weapons improve the chances of apprehending } \\
\text { terrorism suspects and bringing them to justice, and } \\
\text { may also allow soldiers to capture key evidence or } \\
\text { enemy materiel that might have been destroyed by } \\
\text { conventional weapons. }\end{array}$ \\
\hline $\begin{array}{l}\text { Minimize opportunities for } \\
\text { our adversaries to provoke } \\
\text { negative public opinion } \\
\text { against our cause }\end{array}$ & $\begin{array}{l}\text { Especially relevant. Sensitivity to casualties could be } \\
\text { heightened and heavy-handed tactics could be seen to } \\
\text { blur distinction between U.S. and terrorists, } \\
\text { undermining public support and support of allies. The } \\
\text { potential for non-lethal weapons to reduce casualties } \\
\text { among innocent civilians is particularly important } \\
\text { here. Especially important too for preemptive strikes, } \\
\text { as these tend to provoke negative international } \\
\text { reaction. }\end{array}$ \\
\hline $\begin{array}{l}\text { Limiting collateral damage } \\
\text { and post-war rebuilding and } \\
\text { aid for which the U.S. often } \\
\text { feels responsible }\end{array}$ & $\begin{array}{l}\text { Some relevance, depending on the nature of the } \\
\text { particular operation. For example, special operations } \\
\text { raids, whether using lethal or non-lethal means, are } \\
\text { unlikely to cause the kind of damage that might } \\
\text { become a significant economic issue. Non-lethal } \\
\text { weapons, on the other hand, could provide an } \\
\text { alternative to the destruction of property caused by, } \\
\text { for example, a large-scale bombing campaign. }\end{array}$ \\
\hline $\begin{array}{l}\text { WMD neutralizer (pre-empt } \\
\text { w/o collateral damage) }\end{array}$ & $\begin{array}{l}\text { Especially relevant. WMD are seen as greatest danger } \\
\text { posed by terrorists. }\end{array}$ \\
\hline
\end{tabular}




\section{Table 6: Drawbacks of Non-Lethal Weapons Against Terrorists}

\begin{tabular}{|c|c|}
\hline Drawback & Relevance to Counter-Terrorism Operations \\
\hline Unrealistic expectations & $\begin{array}{l}\text { Possible special relevance since war against terrorism in } \\
\text { less likely to feature large force-on-force engagements } \\
\text { where casualties are expected. }\end{array}$ \\
\hline $\begin{array}{l}\text { Potential for the enemy to } \\
\text { fight again }\end{array}$ & $\begin{array}{l}\text { Especially relevant. The threat created by terrorists, } \\
\text { who often display fanatical devotion to their cause and a } \\
\text { willingness even to commit suicide, may only be } \\
\text { stopped by a forceful application of lethal force. }\end{array}$ \\
\hline Deterrent value diminished & $\begin{array}{l}\text { Depends on motivation of terrorists. As death is not a } \\
\text { deterrent for many terrorists, it is possible that the } \\
\text { humiliation caused by their capture using non-lethal } \\
\text { weapons may be an even greater deterrence. This } \\
\text { psychological aspect of non-lethal weapons needs more } \\
\text { research. }\end{array}$ \\
\hline $\begin{array}{l}\text { Failure to overcome our } \\
\text { adversary's hostile will }\end{array}$ & $\begin{array}{l}\text { Another unknown. What is required to cause terrorist } \\
\text { organizations to give up terrorism as a means for } \\
\text { achieving their objectives needs to be considered. }\end{array}$ \\
\hline Proliferation issues & $\begin{array}{l}\text { Potentially relevant. Non-lethal technologies falling } \\
\text { into the hands of those we intend to use them against } \\
\text { could create a danger that they use them against us. } \\
\text { However, the utility of these weapons may be only } \\
\text { effective if combined with a high degree of doctrine } \\
\text { development and training. As the U.S. places special } \\
\text { emphasis in this area, it may neutralize an adversary's } \\
\text { ability to make an effective counter to our forces. }\end{array}$ \\
\hline The lure of adventurism & $\begin{array}{l}\text { No special relevance as presumably U.S. forces would } \\
\text { be committed to action whenever the threat of terrorism } \\
\text { is perceived to warrant the risk, regardless of whether } \\
\text { non-lethal technology is available. }\end{array}$ \\
\hline
\end{tabular}


52...Non-Lethal Weapons 


\section{Conclusion}

The 2001 Quadrennial Defense Review report describes a shift from a "threat-based" to a "capabilities-based" approach to defense-one that focuses on the capabilities the U.S. might have to face in the future, rather than specifics about which opponents we might face. It calls for identifying capabilities that U.S. forces will need to deter and defeat adversaries who will "rely on surprise, deception, and asymmetric warfare" to achieve their objectives. ${ }^{135}$ To achieve these goals, the report calls for a "broad portfolio" of military capabilities that exploit the U.S. technological advantages and its ability to "integrate highly distributed military forces in synergistic combinations for highly complex joint military operations." ${ }^{36}$ Further, the defense strategy calls for the "transformation of the U.S. military and defense establishment over time," and urges DOD leaders to recognize that continuing "business as usual...is not a viable option given the new strategic era and the internal and external challenges facing the U.S. military." "137 Whether non-lethal weapons present a significant answer to this call to redesign national defense needs to be seriously considered. In this regard, the JMAA panel's report marks a significant leap forward in the assessment of nonlethal weapons and their applicability on tomorrow's battlefield. While highlighting their potential, the report also noted the deficiencies of the current capabilities and efforts to field non-lethal weapons. It stated that current non-lethal capabilities are "extremely restricted in range" and are “distinctly oriented towards self-protection."138 Further, the panel noted that systems under development do not address large or area targets and that non-lethal capabilities aimed at addressing an adversary's WMD production, transportation, and employment, deemed to be a critical contribution of these weapons, are shortfalls not being addressed. Though not a substitute for lethality, a thorough examination of the potential advantages and disadvantages they offer at the strategic level is needed to determine whether their unique capabilities make them a suitable candidate for broad inclusion in our $21^{\text {st }}$ Century capabilities-based force structure. There is a growing consensus that non-lethal weapons are needed, at least at the tactical level, and for operations at the lower end of the spectrum of conflict, such as for peacekeeping operations. And as seen from the previous section of this report, they may offer substantial 
strategic advantages as a component of the war on terrorism. Whether they will become a more fundamental component of America's military capabilities, stretching across all the full spectrum of conflict including offensive operations, depends on the emphasis given them by senior leaders. We're off to a good start, but it's only a start. Non-lethal weapons may not ever become the wonder weapons envisioned by their most optimistic proponents, but boosting the effort dedicated to bringing them to the battlefield seems like a prudent investment for a technology that may prove to be an extremely useful tool in achieving our national objectives. In time, as technology, doctrine, and experience with these new tools of warfare coalesces and matures, they may indeed prove to be the weapons of choice for tomorrow's warrior. 


\section{Notes}

1 Department of Defense, Quadrennial Defense Review Report (QDRR) 2001 (Washington D.C.: Office of the Secretary of Defense, 30 September 2001), v.

2 Ibid., 29.

${ }^{3}$ Ibid., 29.

4 DOD Policy Directive (DODPD) 3000.3, Policy for Non-lethal Weapons, 9 July 1996, 3.1.

${ }^{5}$ John B. Alexander, Future War: Non-Lethal Weapons in TwentyFirst-Century Warfare (New York: St. Martin's Press, 1999), 5.

${ }^{6}$ DODPD 3000.3, 4.2.

${ }^{7}$ Ibid.

8 John L. Barry, et al., Non-Lethal Military Means: New Leverage for a New Era, Harvard University National Security Program Policy Analysis Paper 94-01, 5.

${ }^{9}$ DODPD 3000.3, 3.2.

10 Joint Publication 1-02, Department of Defense Dictionary of Military and Associated Terms, defines electronic warfare as "any military action involving the use of electromagnetic and directed energy to control the electromagnetic spectrum or to attack the enemy." A subdivision of electronic warfare is electronic attack, which uses "electromagnetic energy, directed energy, or anti-radiation weapons to attack personnel, facilities, or equipment with the intent of degrading, neutralizing, or destroying enemy combat capability and is considered a form of fires.”

${ }^{11}$ Alexander, 16.

${ }^{12}$ Ibid., 17.

13 Ibid., 17.

14 R.W. Rogers, "Kernan Tasked with Transforming Military," Newport News, 5 August 2001, available on-line from Hhttp://pqasb.pqarchiver.com/dailypress/index.htmlH.

${ }^{15}$ Joint Non-Lethal Weapons Program Non-Lethal Weapons Joint Mission Area Analysis/Joint Mission Need Analysis (JMAA/JMNA), Final Report, December 2000, A-25.

${ }^{16}$ Barry, 5. 


\section{Notes}

17 Nick Lewer and Steven Schofield, Non-Lethal Weapons: A Fatal Attraction?: Military Strategies and Technologies for 21St-Century Conflict (London: Zed Books, 1997), 63.

18 Though the intent and result of the Jericho attack was evidently destruction of the city, and therefore it is not an example of a non-lethal weapon, acoustic weapons tuned to non-lethal energy levels meet DOD criteria. For an excellent discussion on this type of weapon, see John B. Alexander, Future War: Non-Lethal Weapons in Twenty-First-Century Warfare (New York: St. Martin's Press, 1999).

${ }^{19}$ Barry, 5.

${ }^{20}$ Lewer and Schofield, 59-65.

${ }^{21}$ Ibid., 66.

22 Specialist T.S. Jarmusz, "Soldiers Train with Non-Lethal Weapons," Talon 7, no. 26, (30 June 2001): 6, available from Hhttp://www.tfeagle.army.mil/tfetalon/talon_archive/2001/talon\%202001-06-30.pdfH.

${ }^{23}$ For example, see Air University Library bibliography compiled by Joan Hyatt at Hhttp://www.au.af.mil/au/aul/bibs/soft/softkill.htmH.

24 Steven Metz, "Non-Lethal Weapons: A Progress Report," Joint Force Quarterly 28, (Spring/Summer 2001): 19, available from Hhttp://www.dtic.mil/doctrine/jel/jfq_pubs/spring01.htmH.

${ }^{25}$ Alexander, 22.

26 “Joint Non-Lethal Weapons Program History,” Joint Non-Lethal Weapons Directorate website, 15 July 2003, n.p.; on-line, Internet, 31 July 2003, available at Hhttp://www.jnlwd.usmc.mil/history.aspH.

${ }^{27}$ Alexander, 24.

${ }^{28}$ JNLWP History.

${ }^{29}$ Alexander, 24.

${ }^{30}$ Ibid., 20. Editor's note: Many reliable sources present Somali casualty numbers in the 1000-3000 range for the battle of Mogadishu.

31 Ibid., 23.

${ }^{32}$ From the Joint Non-Lethal Warfare Directorate webpage located at: http://www.jnlwd.usmc.mil/default2.htm

${ }^{33}$ DODPD 3000.3, 5.7.

34 Joint Service Memorandum of Agreement for the DOD Non-Lethal Weapons Program, 23 June 1999, 3.5.4. Editor's note: The JS MOA for the DOD NLW Program was updated on 10 May 2002. 


\section{Notes}

35 JMAA/JMNA Final Report, i.

${ }^{36}$ Chairman of the Joint Chiefs of Staff Instruction (CJCSI) 3010.02, 15 April 2001, Joint Vision Implementation Master Plan (JIMP), states, "The purpose of the JIMP is to define a process that will translate emerging joint operational concepts into joint warfighting capabilities as a result of joint experimentation and assessment recommendations. The JIMP describes the generation, coordination, approval, and implementation process for joint Doctrine, Organizations, Training, Materiel, Leadership and Education, Personnel, and Facilities (DOTMLPF) recommendations and defines roles and responsibilities within that process." Also, Chairman of the Joint Chiefs of Staff Instruction (CJCSI) 3170.01B, April 2001, Requirements Generation System states: "the Requirements Generation System, along with the Acquisition Management System and the Planning, Programming, and Budgeting System, form the Department of Defense's three principal decision support systems. The requirements generation system produces information for decision makers on the projected mission needs of the warfighter. These mission needs are defined in broad operational terms in an Mission Needs Statement (MNS) document. MNSs are prepared for needs that develop into warfighter's operational requirements that could result in new defense acquisition programs.”

${ }^{37}$ JMAA/JMNA Final Report, ii-iii.

${ }^{38}$ Ibid., iii.

${ }^{39}$ Ibid., v.

${ }^{40}$ Ibid., v-vi.

${ }^{41}$ Ibid., A-1.

${ }^{42}$ Ibid., 15.

${ }^{43}$ Ibid., 14.

${ }^{44}$ Ibid., 16-18. Source quoted in entirety.

${ }^{45}$ Susan D. Levine, Deputy Director for Technology, Joint Non-Lethal Weapons Directorate, personal email “Re: NLW,” 4 Feb 2003.

${ }^{46}$ Ibid.

47 "Marines, SwRI to demonstrate new anti-traction system for controlling crowds and securing facilities," Southwest Research Institute News Release, 10 December 2001, available from Hhttp://www.swri.org/9what/releases/mds.htmH. 


\section{Notes}

48 DOD Instruction (DODI) 5000.2, Operation of the Defense Acquisition System (Including Change 1), 4 January 2001, 4.7.2.4.2.4.

49 "Objective Individual Combat Weapon," Federation of American Scientists Military Analysis Network, 8 August 2000, n.p.; on-line, Internet, 31 July 2003, available from Hhttp://www.fas.org/man/dod101/sys/land/oicw.htmH.

${ }^{50}$ Camilo A. Sanchez, "Non-Lethal Airburst Munition(s) for Objective Individual Combat Weapon,” 2001 NDIA Joint Services Small Arms Symposium, Little Rock, Arkansas, 15 August 2001, available from Hhttp://www.dtic.mil/ndia/2001smallarms/sanchez.pdfH.

51 “The Department of Defense's Advanced Concept Technology Demonstrations,” Congressional Budget Office, September 1998, available from

Hhttp://www.cbo.gov/showdoc.cfm?index $=865 \&$ sequence $=0$ \&from $=1 \mathrm{H}$.

52 "Fiscal 2001 Advanced Concept Technology Demos Announced," US DOD News Release No. 051-01, 2 February 2001, available from Hhttp://www.defenselink.mil/news/Feb2001/b02022001_bt051-01.htmlH.

53 “Active Denial Technology Fact Sheet," Air Force Research Laboratory Directed Energy Directorate, March 2001, available from Hhttp://www.de.afrl.af.mil/factsheets/activedenial.htmlH.

${ }^{54}$ Raytheon Missile Systems, "Extended Range Guided Munition (ERGM) Fact Sheet," (Tuscon, AZ: 2001-2003), available from Hhttp://www.esys.com/products/ergm/ref_docs/ergm.pdfH. According to the Raytheon Fact Sheet, the ERGM is a precision-guided projectile with a range goal of greater that 50 nautical miles and accuracy of less than 20M circular error probability. It features fast global positioning system acquisition and a high anti-jam design that enables use of a low-cost inertial measuring unit. The ERGM will support the simultaneous impact of multiple projectiles.

${ }^{55}$ Levine, personal email.

${ }^{56}$ Major N.D. Montgomery, Chief, Health Effects Assessment, Joint Non-Lethal Weapons Directorate, interviewed by author 9 December 2001.

57 JMAA/JMNA Final Report, B-1-11.

${ }^{58}$ Carl Von Clausewitz, On War, trans. Michael Howard and Peter Paret (Princeton N. J.: Princeton University Press, 1976), 88. 


\section{Notes}

${ }^{59}$ Colin S. Gray, "Weapons for Strategy Effect: How Important is Technology?” (Maxwell AFB, Ala: Center for Strategy and Technology Occasional Paper No. 21), 2001, 2.

60 “Joint Concept for Non-Lethal Weapons," USMC Warfighter Requirements Division, 5 January 1998, available from Hhttp://192.156.75.102/nonleth.htmH.

${ }^{61}$ JMAA/JMNA Final Report, Annex B.

${ }^{62}$ Ibid., Annex A, Appendix 4.

${ }^{63}$ Louis A. Manzo, "Morality in War Fighting and Strategic Bombing in World War II,” Air Power History, Vol. 39, No. 3, Fall 1992, 35-50, in Air War College Resident Programs Leadership and Ethics Book 2,

AcademicYear 2002, 60.

${ }^{64}$ Ibid.

65 George P. Schultz, “The Ethics of Power," Ethics and American Power, 1985, Chapter 2, in Air War College Resident Programs Strategy, Doctrine and Air Power Course Book, Academic Year 2002, 579.

66 Joint Publication 1, Joint Warfare of the Armed Forces of the United States, 14 November 2000, V-2.

${ }^{67}$ Ibid., 2.

${ }^{68}$ Richard L. Garwin, et al., Non-Lethal Technologies: Progress and Prospects, Report of an Independent Task Force Sponsored by the Council on Foreign Relations, (New York: Council on Foreign Relations, Inc., 1999), executive summary.

69 Chairman of the Joint Chiefs of Staff, Joint Vision 2020, (Washington, D.C.: US Government Printing Office, June 2000), available on-line from Hhttp://www.dtic.mil/jointvision/H, 1.

${ }^{70}$ Ibid., 2.

${ }^{71}$ Ibid.

${ }^{72}$ Levine, personal email.

${ }^{73}$ Ibid.

${ }^{74}$ Wesley K. Clark, Waging Modern War (New York: Public Affairs, 2001), 458.

${ }^{75}$ DODPD 3000.3, 2.

${ }^{76}$ Draft Program Research and Development Announcement of The Air Force Research Laboratory, Munitions Directorate Ordnance Division 


\section{Notes}

(AFRL/MNMI), available from Hhttp://www.fas.org/man/dod101/sys/smart/docs/Adwprda.htmH.

${ }^{77}$ See, for example, the Global Security, Inc. website available from Hhttp://www.globalsecurity.org/military/systems/munitions/adw.htmH.

${ }^{78}$ Benjamin S. Lambath, The Transformation of American Air Power (Ithaca, N.Y.: Cornell University Press, 2000), p. 205.

${ }^{79}$ DODPD 3000.3, 4.2.

80 JMAA/JMNA Final Report, D-10.

${ }^{81}$ Lieutenant Colonel Martin N. Stanton, What Price Sticky Foam?, Naval Institute Proceedings 122, no. 1 (January 1996). Available from Hhttp://carlislewww.army.mil/usawc/Parameters/96autumn/stanton.htmH.

${ }^{82}$ C. T. Clyne, "Andersonville and Other Civil War Prisons, North and South,” available from http://users.aol.com/cinticwrt/anders.html

${ }^{83}$ Carl Von Clausewitz, On War, trans. Michael Howard and Peter Paret (Princeton N. J.: Princeton University Press, 1976), 90.

84 Fred C. Ikle, Every War Must End, (New York: Columbia University Press, 1991), 108.

85 “Transcript of 'Usamah Bin-Ladin, the Destruction of the Base' Interview with Usamah Bin-Ladin,” conducted by Jamal Isma'il (no date) and presented by Salah Najm, 10 June 1999, on-line, Internet, 1 August 2003, available from Hhttp://www.robertfisk.com/usama_interview_jamaal_ismail.htmH.

${ }^{86}$ Carl Von Clausewitz, On War, trans. Michael Howard and Peter Paret (Princeton N. J.: Princeton University Press, 1976), 75.

87 Stanton.

${ }^{88}$ Clausewitz, 76.

${ }^{89}$ Ikle, 12.

${ }^{90}$ Quoted in Howard M. Hensel, The Sword of the Union: Federal Objectives and Strategies during the American Civil War, (Montgomery, Alabama: USAF Air Command and Staff College, 1989), 220.

${ }^{91}$ Lewer and Schofield, 97.

${ }^{92}$ Alexander, 180.

${ }^{93}$ DODPD 3000.3, 4.5.

${ }^{94}$ Fenton, Overview Briefing. 


\section{Notes}

95 Article 6, Constitution for the United States of America, available from Hhttp://www.usconstitution.com/Read.htmH.

${ }^{96}$ DODPD 3000.3, 5.6.2.

97 JMAA/JMNA Final Report, D-10.

98 Abba Eban, Israeli Ambassador to the United States, 1957, quoted by Robert J. Bunker in "Non-Lethal Weapons: A British View," Military Review 78 (July-August 1998): 86-87.

99 Lieutenant Colonel Margaret-Anne Coppernoll and Xavier K. Maruyama, "Legal and Ethical Guiding Principles and Constraints Concerning Non-Lethal Weapons Technology and Employment," Proceedings to the NDIA Non-lethal Defense III Conference, Johns Hopkins University, MD, 25 February 1998, 2.

${ }^{100}$ Lewer and Schofield, 83.

101 Laws of War: Laws and Customs of War on Land (Hague IV); October 18, 1907, Article 23, available from Hhttp://www.yale.edu/lawweb/avalon/lawofwar/hague04.htmH.

102 "Protocol Additional to the Geneva Conventions of 12 August 1949, and relating to the Protection of Victims of International Armed Conflicts (Protocol 1)," Article 51, Office of the High Commission for Human Rights, adopted 8 June 1977 by the Diplomatic Conference on the Reaffirmation and Development of International Humanitarian Law applicable in Armed Conflicts. Available from Hhttp://www.unhchr.ch/html/menu3/b/93.htmH

Indiscriminate attacks are prohibited. Indiscriminate attacks are:

(a) Those which are not directed at a specific military objective;

(b) Those which employ a method or means of combat which cannot be directed at a specific military objective; or

(c) Those which employ a method or means of combat the effects of which cannot be limited as required by this Protocol; and consequently, in each such case, are of a nature to strike military objectives and civilians or civilian objects without distinction.

Among others, the following types of attacks are to be considered as indiscriminate:

(a) An attack by bombardment by any methods or means which treats as a single military objective a number of clearly separated and distinct military objectives located in a city, town, village or other area containing a similar concentration of civilians or civilian objects; and 


\section{Notes}

(b) An attack which may be expected to cause incidental loss of civilian life, injury to civilians, damage to civilian objects, or a combination thereof, which would be excessive in relation to the concrete and direct military advantage anticipated.

103 Protocol 1, Article 37.

104 DOD Instruction (DODI) 5000.2, Operation of the Defense Acquisition System (Including Change 1), 4 January 2001, states the following:

4.7.3.1.4. DOD acquisition and procurement of weapons and weapon systems shall be consistent with all applicable domestic law and all applicable treaties, customary international law, and the law of armed conflict (also known as the laws and customs of war).... The Head of each DOD Component shall ensure that the Component's General Counsel or Judge Advocate General, as appropriate, conducts a legal review of the intended acquisition of a potential weapon or weapon system to determine that it is consistent with U.S. obligations. The review shall be conducted again before the award of a system development and demonstration contract for the weapon or weapon system and before the award of the initial production contract. Files shall be kept permanently. Additionally, legal reviews of new, advanced or emerging technologies that may lead to development of weapons or weapon systems are encouraged.

105 Air Force Instruction (AFI) 51-402, Weapons Review, 13 May 1994, 1.1.1.

106 AFI 51-402, Weapons Review, para. 1.1.2. states, "The Office of the Assistant Secretary of the Air Force for Acquisition (SAF/AQ) will ensure TJAG, or TJAG's designee, reviews, for legality, all weapons, whether new acquisitions or modifications of existing weapons, at the earliest possible stage in the acquisition process, including the research and development stage.”

107 JMAA/JMNA Final Report, D-1-1.

${ }^{108}$ Coppernoll and Maruyama, 1-2. 


\section{Notes}

109 Ibid.

${ }^{110}$ Ibid.

111 JMAA/JMNA Final Report, D-6.

112 Convention on the Prohibition of the Development, Production, Stockpiling and Use of Chemical Weapons and On Their Destruction (CWC), Paris, 13 January 1993, Article 1, para. 5, available from Hhttp://www.opcw.org/html/db/cwc/eng/cwc_frameset.htmlH.

${ }^{113}$ CWC, Article 2, para. 7.

114 The Naval Treaty Implementation Program website is an excellent source of information for the various chemical and biological agreements and is available from

Hhttp://www.nawcwpns.navy.mil/ treaty/index.htmlH.

${ }^{115}$ Ibid.

${ }^{116}$ Convention on the Prohibition of the Development, Production and Stockpiling of Bacteriological (Biological) and Toxin Weapons and on Their Destruction, Article 1, 26 March 1975, available from Hhttp://projects.sipri.se/cbw/docs/bw-btwc-mainpage.htmlH.

${ }^{117}$ Ambassador Donald Mahley, U.S. Special Negotiator for Chemical and Biological Arms Control Issues, "Statement by the United States to the Ad Hoc Group of Biological Weapons Convention States Parties,” Geneva, Switzerland, 25 July 2001, available from Hhttp://www.state.gov/t/ac/rls/rm/2001/5497.htmH.

Also see Hhttp://www.nawcwpns.navy.mil/ treaty/BWC.htmlH.

${ }^{118}$ Coppernoll and Maruyama, 1.

119 Ibid., 3.

120 Stanton.

121 JMAA/JMNA Final Report, A-41.

${ }^{122}$ Ibid., D-7.

${ }^{123}$ Ibid., D-7.

${ }^{124}$ Ibid., C-1.

${ }^{125}$ Ibid., Annex C.

${ }^{126}$ Ibid., C-21-22.

${ }^{127}$ QDRR 2001, 40.

128 JMAA/JMNA Final Report, 43.

${ }^{129}$ Ibid., ii. 


\section{Notes}

${ }^{130}$ United States Code, Title 22-Foreign Relations and Intercourse, Section 2656f(d), quoted in U.S. Department of State, Patterns of Global Terrorism 2000," (Washington, D.C.: U.S. Government Printing Office, April 2003), xiii, available from Hhttp://www.state.gov/s/ct/rls/pgtrpt/2002/H. "Noncombatants" are interpreted to include off-duty military personnel and attacks on armed military personnel or installation when a state of military hostilities does not exist.

131 Ibid. xi.

132 President George W. Bush, address to a Joint Session of Congress and the American People, United States Capitol, Washington, D.C., 20 September 2001, available from

Hhttp://www.whitehouse.gov/news/releases/2001/09/20010920-8.htmlH.

${ }^{133}$ Boaz Ganor, Executive Director of International Policy Institute for Counter-Terrorism, remarks to Air War College Regional Studies Group at Tel-Aviv, Israel, 12 March 2002.

134 Secretary of Defense Donald Rumsfeld, “ $21^{\text {st }}$ Century Transformation of U.S. Armed Forces," remarks to National Defense University, Fort McNair, Washington, D.C., 31 January 2002, available from Hhttp://www.defenselink.mil/speeches/2002/s20020131secdef.htmlH.

${ }^{135}$ QDRR 2001, 14.

${ }^{136}$ Ibid., 15.

${ }^{137}$ Ibid., 16.

138 JMAA/JMNA Final Report, 40. 